\title{
Modulation of Dendritic Cell Responses by Parasites: A Common Strategy to Survive
}

\author{
César A. Terrazas, ${ }^{1}$ Luis I. Terrazas, ${ }^{1}$ and Lorena Gómez-García ${ }^{2}$ \\ ${ }^{1}$ Unidad de Biomedicina, Facultad de Estudios Superiores Iztacala, Universidad Nacional Autónoma de México (UNAM), \\ 54090 Tlalnepantla, Estado de México, Mexico \\ ${ }^{2}$ Department of Immunology, Instituto Nacional de Cardiología "Ignacio Chávez", Secretaria de Salud, Juan Badiano no. 1, \\ Col Sección XVI, 14080 Tlalpan, México D.F., Mexico \\ Correspondence should be addressed to Lorena Gómez-García, lorena.gomez@cardiologia.org.mx
}

Received 21 August 2009; Accepted 18 November 2009

Academic Editor: Abhay R. Satoskar

Copyright ( ) 2010 César A. Terrazas et al. This is an open access article distributed under the Creative Commons Attribution License, which permits unrestricted use, distribution, and reproduction in any medium, provided the original work is properly cited.

\begin{abstract}
Parasitic infections are one of the most important causes of morbidity and mortality in our planet and the immune responses triggered by these organisms are critical to determine their outcome. Dendritic cells are key elements for the development of immunity against parasites; they control the responses required to eliminate these pathogens while maintaining host homeostasis. However, there is evidence showing that parasites can influence and regulate dendritic cell function in order to promote a more permissive environment for their survival. In this review we will focus on the strategies protozoan and helminth parasites have developed to interfere with dendritic cell activities as well as in the possible mechanisms involved.
\end{abstract}

\section{Introduction}

Dendritic cells (DCs) control the development of adaptive immune responses due to their remarkable ability to integrate signals coming from the environment, deliver this information to naive $\mathrm{T}$ cells, and in turn activate them inducing the appropriate response for the initial stimuli $[1,2]$. During infection, the responses induced by DC are critical to control and eliminate the invading agent, the infection itself being the inducer of DC activity. DC maturation and activation involves upregulation of several molecules that play main roles in costimulation and antigen presentation to $\mathrm{T}$ cells such as CD80, CD86, CD40, and major histocompatibility complex II (MHC-II), along with the release of cytokines that influence the type and intensity of the immune response [2-4]. Mature DCs are fully potent antigen-presenting cells (APCs) that will prime naïve $\mathrm{T}$ cells inducing their differentiation and proliferation $[1,5]$. Protozoan parasites can activate and induce the maturation of different DC subsets and in most cases the activity of these cells leads to a response that is effective in controlling the infection [6-8]. The case of helminthes is more complex since most reports show a partial maturation of DC in response to these parasites or their antigens that does not contribute with parasite elimination [9-11]. In any case, it has been shown that both, helminthes and protozoan, are capable to interfere with DC activity promoting a more permissive environment for their own survival inside their host [11-14]. Different interactions of parasite-derived molecules with receptors on DC such as Toll-like receptors (TLRs), C-type lectin receptors (CLRs), and others seem to be the key event in the mechanisms that ultimately will lead to the altered function in these cells [15-18]. In this review we will focus on some important protozoan and helminth parasites and their ability to modify DC function, the implications of such modulation, and the possible mechanisms involved. We will discuss the differences and similarities in the interference with DC activity between these two distinct parasite groups.

\section{Protozoan Parasites}

2.1. Plasmodium. It has been shown that different species of Plasmodium sp. can modulate the response of DC 
$[6,13,19-22]$. While infection by some nonlethal strains seems to induce the activation, maturation, and secretion of important proinflammatory cytokines such as IL-12 by DC $[6,22]$, infection not only with lethal strains such as $P$. yoelii YM or $P$. berghei but also with the nonlethal P. vivax can impair DC function. Modified DC function by Plasmodium species can be achieved through varied mechanisms. Some of these mechanisms involve a decrement in total DC numbers as well as an altered ratio of myeloid versus plasmacytoid cell subsets, the latter being probably involved in the induction of a regulatory phenotype mediated by regulatory $\mathrm{T}$ cells (Tregs) and IL-10 production [12]. Other studies have reported null or reduced capacity of Plasmodium-exposed DCs to prime T cells [6, 21-24], situation that could be related with the inability of these DCs to establish prolonged interactions with naïve CD4+ $\mathrm{T}$ cells [23]. Interestingly, DCs from infected mice with lethal or no lethal strains show an impairment in their response to TLR stimulation, as a marked reduction in IL12 secretion is observed upon stimulation with LPS, CpG, or poly:IC, resulting in some cases, in the inversion of the IL-12/IL-10 secretion pattern displayed by DC $[6,21,24]$. Since these changes can occur as malaria infection progresses [21], altogether these data suggest that Plasmodium has the ability to switch an aggressive immune environment into a more permissive one for its survival. Other effects that Plasmodium has on the function of DC have been reported. These effects can be attributed to the invading species, the parasite life stages, or the products they release. For example, a preferential increment in $\mathrm{CD}^{-} \mathrm{DC}$ in spleen is observed in the acute phase of $P$. chabaudi infection. Importantly, only $\mathrm{CD}^{-}$dendritic cells induce proliferation of merozoite surface protein- (MSP1-) specific T cells, and since these $\mathrm{T}$ cells produce considerable levels of IL- 4 and IL-10, it is suggested that the change from a Th1 to a Th2 response that takes place in $P$. chabaudi infection [25] can be attributed to these already modified DC populations [13].

Maturation of human monocyte-derived DC (MDC) through CD40L can be also prevented by $P$. falciparum merozoites. These DCs show a diminished IL-12p70 secretion but enhance IL-10 production and prime CD4+ naive $\mathrm{T}$ cells to produce higher levels of IL-10 and lower levels of IFN- $\gamma$. These effects by merozoites on DC seem to involve the activation of the extracellular-signal regulated kinase (ERK) pathway [26]. In contrast, in the same study, DC exposed to $P$. falciparum infected erythrocytes respond to CD40 signaling secret proinflammatory cytokines that lead to a proinflammatory response by naive CD4+ T cells, and this time, p38 mitogen-activated protein (MAP) kinase plays an essential role. These evidences indicate that $P$. falciparum uses distinct kinase pathways to modulate the activity of DC [26]. Moreover, those findings also indicate a different activity on DC function between the whole parasite and its products.

DC maturation can also be compromised in vivo during the last stage of $P$. yoelii infection and in vitro when DC are cultured in the presence of $P$. yoelii-infected erythrocytes [27]. Interestingly, the presence of the complete parasite is not necessary to interfere with DCs function and byproducts of hemoglobin degradation mediated by $P$. falciparum such as hemozoin can also modulate the activity of DC. This malarial pigment inhibits the differentiation and maturation of MDC, reducing the expression of major MHC-II and the costimulatory molecules CD83, CD80, CD54 and CD40 [28, 29]. T cells activated in the spleen by hemozoin-containing DC, are not completely functional since they can not secrete cytokines or migrate to B-cells follicles [19].

More, recently it was shown that soluble factors released by $P$. yoelii or $P$. falciparum-infected erythrocytes can inhibit LPS induced maturation of DC and change their cytokine secretion profile resulting in a failure to produce IL-12 [27]. Induction of regulatory DC that in turn promotes a Treg response is another mechanism by which malaria parasites may subvert host immune systems. Surprisingly, this effect appears to be mediated by recognition of the parasite's molecules by TLR9 $[12,30,31]$.

Considering the importance of $\mathrm{IL}-12$ and the Th1 response along with the full activation of DC to prime efficiently $\mathrm{T}$ cells in the immune response against Plasmodium species, the modulatory effects over DC function discussed above, seem to be an effective evasion strategy actively induced by Plasmodium parasites that certainly can influence the outcome of the infection.

There is evidence supporting the interaction of Plasmodium parasites with several receptors expressed by DC. For example, among the different surface antigens expressed on $P$. falciparum, the Plasmodium falciparum erythrocyte membrane protein 1 (PfRBC-1) seems to play a main role [32]. This protein can mediate adherence to DC through the interaction with the Scavenger receptor CD36 [33] but also through the proteoglycan molecule, chondroitin sulfate A (CSA) [34, 35]. However, the interactions of PfRBC -1 seem not to be related with the interference of $P$. falciparum with DC function, in fact; in vitro studies have shown that modulation of DC responses might not need contact between these cells and the infected erythrocytes [35], opening the possibility for parasite-soluble factors playing a major role. This is well exemplified by the interaction of Plasmodium parasites and TLR2, TLR4 and TLR9 which can indeed recognize infected erythrocytes-derived products [36-38]. Soluble extracts from $P$. falciparum and hemozoin (by presenting malaria DNA) can activate DC in a TLR9 dependent fashion, inducing up-regulation of costimulatory molecules and proinflammatory cytokines and chemokines, some of them involved in host resistance against $P$. falciparum [36, 37, 39]. Interestingly, it was recently shown that $P$. yoelii uses the interaction with the same receptor on DC to in turn induce Treg cells, a response that is associated with P.yoelii-immune evasion [30]. This finding indicates that different Plasmodium species may induce different responses through their interaction with TLR9. However, there is still little information about the receptors and ligands involved in the DC downregulation consistently observed in Plasmodium infections or in response to their products. See Table 1 . 
2.2. Leishmania. Clearance and resistance to Leishmania infections is dependent on the development of a Th1 response and the production of IL-12 [40-42], and in this regard, DCs play a critical role [43]. It has been shown that during Leishmania infections, engulfment of amastigotes and promastigotes by DCs leads to their activation and a consequent IL-12 and TNF- $\alpha$ production that can contribute with host resistance $[44,45]$. However, more accurate is the fact that the effect of Leishmania infection on DC maturation and cytokine production could vary for the different Leishmania species and strains; for example, while the uptake of $L$. major promastigotes and amastigotes results in DC maturation and IL-12 production [46, 47], promastigotes of $L$. amazonensis can interfere with DC responses affecting their differentiation and decreasing their ability as APC [48]. Both stages of this specie can reduce CD40 and CD83 surface expression and IL-12p40 production by bone-marrow-derived dendritic cells (BMDCs) in a mechanism that requires the activation of the MAP kinase ERK $[7,49]$. Additionally, IL-12p40, IL-12p70, and IL-6 are downregulated and IL-10 secretion increased when infected DC are treated with LPS [7]. Lack of activation and a reduced IL-12 production by DCs also observed after L. mexicana infection along with a delay in their apoptotic process [50, 51]. L. donovani can also inhibit DCs maturation and modify their CCR7 expression, interfering with their migration to the periarteriolar lymphoid sheath $[52,53]$. Interestingly, some of the regulatory effects that $L$. donovani has on DC depend on the phosphoglycans present in the parasite [52]. In fact, several Leishmania products can also impair DC activity as it has been shown that parasite culture media or lipophosphoglycans (LPGs) from L. major inhibit the motility of murine splenic DC [54] or the migration of Langerhans cells [55], suggesting that Leishmania products may interfere with antigen transportation. L. major phosphoglycans (PGs) are involved in downregulation of IL-12p40 production by DC and in the ability of these cells to induce a Th1 response since these molecules favor IL- 4 and IL-10 but not IFN- $\gamma$ production [56]. Moreover, excreted-secreted antigens of $L$. donovani or L. major induce a slight decrease in the surface expression of CD40, CD86, human leukocyte antigen-DR (HLA-DR), and cell-specific intercellular adhesion molecule3 -grabbing nonintegrin (DC-SIGN) on DC concomitant with a downregulation on IL-10 and IL-12p70 secretion [57]. In the case of L. mexicana, the activity of LPGs on DC function also includes a reduction in IL-12 production that may depend on the impairment on NF- $\kappa \mathrm{B}$ nuclear translocation induced by parasite's antigens [51]. Since the maturation state of DC seems to determine the type of immune response induced in Leishmania infections, where an immature state promotes a Th2 response which does not control the infection and a mature phenotype induces a Th1 response with the subsequent host resistance [58], the interference of these parasites and their products in the maturation process of DC may be critical for parasite survival.

Some studies have shown that activation and production of IL- 12 and IFN- $\alpha / \beta$ by myeloid DC (mDC) and plasmacytoid DC (pDC) after stimulation with L. major, L. brasilienzis, or L. infantum is strictly dependent on TLR9 signaling [59, 60 ] and the maturation of splenic DC is improved by the myeloid differentiation primary response gene 88 (MyD88)signaling pathway, indicating an important role of TLRs in activation of DC by Leishmania [61]. In addition, others found that TLRs such as TLR2 and TLR4 are involved in the response to Leishmania parasites and their products, like LPGs that might signal through TLR2 inducing a TNF- $\alpha$ response [62-64]. Interestingly, a noncharacterized soluble product from L. brasilienzis activates DC in a MyD88independent fashion, suggesting that receptors other than TLRs may play a role in the responses induced by Leishmania products on these cells [65]. But even when interaction of Leishmania sp. parasites or their products with TLRs and probably other receptors can induce the activation of DC, it is still unknown which kinds of molecules, receptors, and pathways are involved in the impairment of function that has been observed in DC exposed to Leishmania parasites, Leishmania LPGs, or Leishmania excreted-secreted products. Therefore, deeper studies in this field should improve our knowledge on Leishmania's strategies to survive the immune response. See Table 1.

\subsection{Trypanosoma. Infection of MDC with Trypanosoma} cruzi induces functional changes in these cells. For example, secretion of IL-12 and TNF- $\alpha$ is impaired and the maturation process induced by LPS is affected, observing a marked reduction in proinflammatory cytokines secretion as well as on the expression of HLA-DR and CD40. Moreover, the same effects are observed when DCs are cultured in the presence of $T$. cruzi-conditioned medium, indicating a modulatory activity of the molecules released by these parasites [66]; in fact, the exposure of DC to T. cruzi-derived GIPL (glycoinositolphospholipids) can also affect the LPSinduced cytokine secretion and expression of costimulatory molecules in similar way that the whole parasite does [67]. Using also in vitro studies, Poncini and colleagues showed that trypomastigote stage of $T$. cruzi fails to activate DCs, these cells become in TGF- $\beta$ and IL-10 producers and are not efficient as lymphocyte stimulators. For these reasons, the authors classify these cells as regulatory DCs [68]. Importantly, in vivo experiments also robustly show the interference of T. cruzi with DC function. At day 14 of an active infection, there is a progressive fall in the number of splenic DCs and this is accompanied with a low expression of the costimulatory molecule CD86, therefore suggesting an immature phenotype. These DCs are unable to migrate to the $\mathrm{T}$ cell area in the spleen or undergo maturation upon LPS stimulation [69]. Interestingly, only the infection with $T$. cruzi-virulent strain RA but not the low-virulence strain K98 affects MHC-II expression on splenic DCs and their capacity to prime $\mathrm{T}$ cells [70], indicating a relation between virulence and a more effective strategy to avoid immunity. This is further supported by the evidence that the infection of the susceptible strain of mice $(\mathrm{BALB} / \mathrm{c})$ with $T$. cruzi induces a downregulation of splenic DC activity. These cells display a diminished CD86 and CD40 expression and a reduced potential to present alloantigens. Importantly, these changes are not observed 
TABLE 1: Protozoan interactions and their regulatory effects on DC.

\begin{tabular}{|c|c|c|c|c|c|c|c|}
\hline Parasite & Product & Putative DC Receptor 9 & & Effect on DC & & $\begin{array}{l}\text { Effect on DC upon TLR } \\
\text { stimuli }\end{array}$ & Ref. \\
\hline \multicolumn{8}{|l|}{ Plasmodium } \\
\hline \multirow[t]{7}{*}{ P. berghei } & Infection & N.D. & $\downarrow$ & Tcell priming & $\downarrow$ & IL-12p70, & \\
\hline & & & & & & endocytic activity & {$[22]$} \\
\hline & & & & & $\uparrow$ & IL-10 & \\
\hline & Infection & TLR9 & & Immature & & & \\
\hline & & & $\downarrow$ & $\begin{array}{l}\mathrm{T} \text { cell priming, shorter } \\
\mathrm{DC} / \mathrm{T} \text { cell interactions }\end{array}$ & $\downarrow$ & CD40, CD86, & \\
\hline & & & & & & MHCII, IL-12p70 & $\begin{array}{c}{[6,23,24,} \\
30]\end{array}$ \\
\hline & & & & & $\uparrow$ & IL-10 & \\
\hline \multirow[t]{3}{*}{ P. yoelii } & & & $\uparrow$ & Treg* & & & {$[21,31]$} \\
\hline & Soluble Factors & N.D. & $\downarrow$ & IL-12 & $\downarrow$ & CD40, CD86, & {$[27]$} \\
\hline & & & & & & MHCII, IL-12 & \\
\hline \multirow[t]{2}{*}{ P. vivax } & Infection & N.D. & $\downarrow$ & mDC:pDC & & N.D. & {$[6,12]$} \\
\hline & & & $\uparrow$ & Treg* & & & \\
\hline \multirow[t]{2}{*}{ P. chabaudi } & Infection & N.D. & $\uparrow$ & CD8- DC & & N.D. & {$[13]$} \\
\hline & & & & Th2* & & & \\
\hline \multirow[t]{6}{*}{ P. falciparum } & Merozoite & N.D. & $\downarrow$ & IL-12p 70, IFN $\gamma^{*}$ & & N.D. & \\
\hline & & & $\uparrow$ & ERK,IL-10, & & & {$[2,20]$} \\
\hline & & & & IL-10* & & & \\
\hline & Hemozoin & N.D. & $\downarrow$ & $\begin{array}{l}\text { Immature } \\
\text { Differentiation } \\
\text { Migration }\end{array}$ & & N.D. & {$[19,28]$} \\
\hline & Soluble extracts & N.D. & & Immature & $\downarrow$ & IL-12 & {$[27]$} \\
\hline & & & $\downarrow$ & IL-12 & & & \\
\hline \multicolumn{8}{|l|}{ Leishmania } \\
\hline \multirow[t]{8}{*}{ L. major } & $\begin{array}{l}\text { Promastigote } \\
\text { Amastigote }\end{array}$ & N.D. & & Immature & & N.D. & {$[55]$} \\
\hline & & & $\downarrow$ & IL-10 & & & \\
\hline & LPGs & TLR2 & $\downarrow$ & Motility Migration & & N.D. & {$[54]$} \\
\hline & PGs & & $\downarrow$ & IL-12p 40, IFN $\gamma^{*}$ & $\downarrow$ & IL-12p40 & {$[56]$} \\
\hline & & & $\uparrow$ & $\mathrm{IL}-4^{*}, \mathrm{IL}-10^{*}$ & & & \\
\hline & ES & N.D. & & Immature & & N.D. & \\
\hline & & & $\downarrow$ & DC-SIGN, IL-10, & & & {$[57]$} \\
\hline & & & & IL-12p70 & & & \\
\hline \multirow[t]{3}{*}{ L. amazonensis } & Promastigote & N.D. & & Immature & & IL-12p40, IL-10 & \\
\hline & & & $\uparrow$ & ERK & $\downarrow$ & IL-12p70, & $\begin{array}{c}{[45,48,49,} \\
65]\end{array}$ \\
\hline & & & $\downarrow$ & IL-12p40 & $\uparrow$ & IL-6 & \\
\hline \multirow[t]{2}{*}{ L. mexicana } & Promastigote & N.D. & & Immature & & N.D. & \\
\hline & & & $\downarrow$ & IL-12 Apoptosis & & & {$[50]$} \\
\hline
\end{tabular}


TABle 1: Continued.

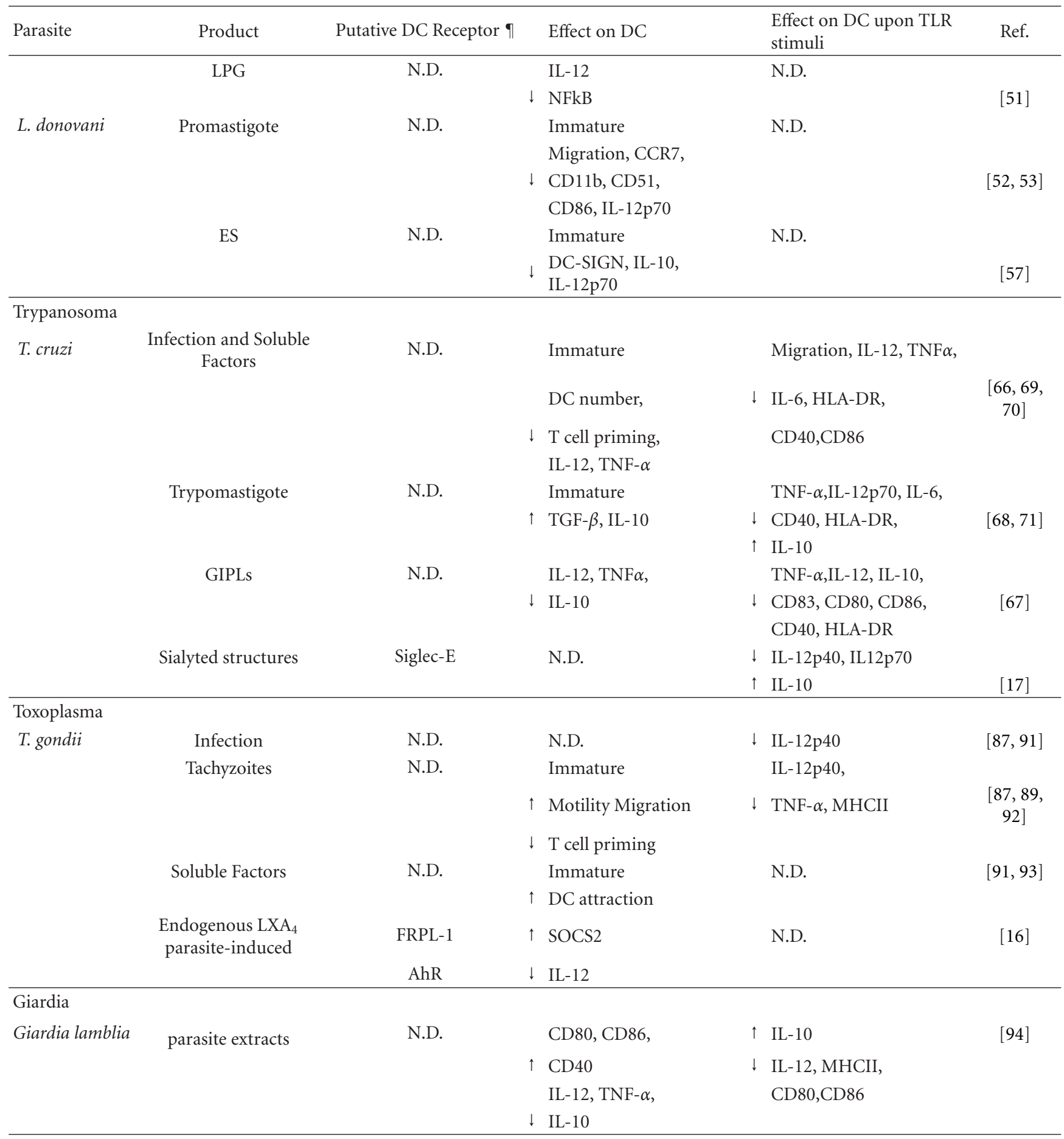

ๆ Involved in modulatory effects on DC.

${ }^{*} \mathrm{~T}$ cell response.

in the $\mathrm{C} 57 \mathrm{Bl} / 6$ mice, a strain capable to survive the acute phase of this infection [71]. Together, these two studies indicate that modulation of certain DC features by T. cruzi depends on both host and parasite genetic backgrounds. They also remind us that even when targeting of DC functions by parasites is an important strategy for immune evasion, it can also unbalance the delicate host/parasite relationship in such a way that infection could be lethal for both.

There are different ways for an intracellular pathogen such as $T$. cruzi interacts with elements of the innate immune system. Macrophages and DCs are cells that 
can be infected by this parasite; nevertheless; when these cells become activated by TLR signaling, through either the adaptor molecules MyD88 or TIR-domain-containing adapter-inducing interferon- $\beta$ (TRIF), both cell types are less prone to allow parasite replication with IFN- $\beta$ playing an important role in parasite clearance [72]. Different molecules derived from T. cruzi can be recognized by TLRs. Glycosylphosphatidylinositol (GPIL) anchors from this protozoan parasite trigger TLR2-dependent antiparasite responses in macrophages [73] while T. cruzi DNA can induce their activation by interaction with TLR9 [74]. Indeed, the combination of TLR2 and TLR9 seems to account for all the protective IFN- $\gamma$ production generated by MyD88dependent signaling pathways in macrophages exposed to live trypomastigotes in vitro [74]. More importantly for this review's topic, the Tc52-released protein from T. cruzi signals via TLR2 and induces DC maturation and production of the inflammatory chemokines IL-8, MCP-1, and MIP$1 \alpha$ [75]. On the other hand, the bradykinin $\mathrm{B}_{2}$ receptors $\left(\mathrm{B}_{2} \mathrm{R}\right)$ in $\mathrm{DC}$ might be also involved in the activation and maturation of these cells, and in turn in the generation of protective responses such as IL-12 production and the development of Th1 immunity [76]. As for other protozoan parasites, the interaction between DC receptors and T. cruzi molecules that lead to downregulated responses in these cells remain poorly understood; however, recent evidence has brought some insights to this phenomena. Erdmann and colleagues demonstrated that sialylated structures from T. cruzi pathogenic Tulahuen and to a less extent the less pathogenic Tehuantepec strain interact with the inhibitory sialic acid-binding protein Siglec-E [17]. This lectin receptor is expressed on DC and interestingly its ligation suppresses the LPS-induced production of IL-12 by these cells. The subsequent $\mathrm{T}$ cell response is also affected since a marked decrease of IFN- $\gamma$ production is observed when Siglec-Eligated DCs are used as APCs. This response could play a role in the immunosuppression observed during T. cruzi infection as well as determining the distinct pathogenicity that these two different strains display [17]. In addition, this finding suggests that the interference with DC function induced by T. cruzi could be achieved through the interaction of lectin receptors with parasite products. See Table 1.

2.4. Toxoplasma. Either live tachyzoites or a soluble tachyzoite extract from Toxoplasma gondii injected into mice induces a rapid and strong production of IL-12 from splenic DC $[77,78]$. This IL-12 response is unusually potent since not even stimuli like LPS or CpG can reach the IL-12 levels induced by T. gondii antigens [79]. Such reaction is mediated by the specific recognition of Toxoplasma-derived profilin by TLR11 expressed specifically on CD8 $\alpha+$ DC [80], although other molecules and other TLRs could be also involved $[81,82]$. Nevertheless, other reports indicate that the potency of the T. gondii to induce IL-12 can be achieved thanks to the engagement of CCR 5 by cyclophylin-18 (C18), a chemokine mimic of MIP- $1 \beta$ derived from the soluble extract of the same parasite [83]. It is, however, important to highlight that the production of high levels of IL-12 secreted by DC in the presence of T. gondii antigens quickly reaches baseline level
(24 h post stimulation) and DCs become refractory to any further exposure to T. gondii in a phenomenon called "DC paralysis" [84]. It is believed that these dramatic changes in the $\mathrm{DC}$ response are due to a parasite strategy that assures the control of a potentially lethal parasite growth and prevents a cytokine-mediated immunopathology, as both scenarios could be deleterious for the host and in turn to the parasite [79]. A line of evidence has further identified a sophisticated T. gondii-induced modulation of the immune response. The parasite-induced production of the eicosanoid lipoxin $\mathrm{A}_{4}$ $\left(\mathrm{LXA}_{4}\right)$ has been linked to the downregulation of IL-12 production by DC [85] in a mechanism that seems to involve the binding of $\mathrm{LXA}_{4}$ to the receptors formyl peptide receptorlike 1 (FRPL-1) or aryl hydrocarbon receptor (AhR) on the same cells [16]. This interaction triggers the expression of the suppressor of cytokine signaling-2 (SOCS-2) that in turn helps to control the proinflammatory and otherwise potentially lethal immune response against $T$. gondii [16]. In line with this idea, in the absence of the AhR receptor (AhR knock out) mice succumb rapidly to ME49 $T$. gondii infection, a situation that is associated with the higher proinflammatory response observed in these animals [86].

In contrast with the evidence discussed above, there are some reports that show that invasion of immature DC by $T$. gondii-living parasites does not induce their activation and renders them also resistant to activation by TLR ligands or CD40L $[87,88]$. The differences in DC responses upon $T$. gondii exposure could be explained by the identification of different DC subpopulations that are indeed involved in the initial response to T. gondii; among those are $\mathrm{CD} 8 \alpha+, \mathrm{CD} 11 \mathrm{~b}+$, and, surprisingly, $\mathrm{pDC}$ [8]. It is noteworthy to consider the findings from Diana and colleagues who reported that soluble factors released from low-virulent strains of T. gondii can inhibit DC maturation [89] while other reports have demonstrated that T. gondiisoluble extract can induce a marked IL- 12 production by DC [77]. Despite the fact that all these apparently contrasting findings may suggest that different soluble molecules from this parasite can provoke varied responses in DC, this is probably due to different soluble antigens interacting with distinct types of receptors.

T. gondii is capable of exploiting parasitism in a remarkable way by using DC to invade other tissues $[88,90]$ or other immune cells [91], promoting in turn the spreading and establishment of the infection. This may be achieved by the early target of these cells by T. gondii tachyzoites, an interaction that seems to modify the DC motility, trafficking, and migration properties as well as their cytokine effector function following TLR stimulation [88-90, 92]; the last one probably renders them unable to activate direct and indirect killing pathways. In addition, T. gondii may use the NK-cell mediating targeting of infected DC to disseminate, allowing viable parasites to enter in NKs that later appeared not to be efficiently targeted by other NK cells [91].

Different mechanisms could be related with the change in trafficking and migration behavior of DC exposed to T. gondii; however, it seems that most of these parasiteinduced alterations are mediated by G-protein signaling pathways $[83,89,92]$. It has been shown that soluble 
factors in excreted-secreted T. gondii antigens appear to possess a chemokine-like activity that attracts immature human [93] and mouse DCs [83] while other factors from a parasite extract can even trigger DC migration towards the chemokine MIP-3 $\beta$ [93]. In both human and mouse cells, the chemokine-like activity might be achieved by the T. gondiiderived chemokine mimic C-18, although other parasite factors could be involved $[83,93]$. In any case, it is likely that this DC attraction might enhance the chances for DC infection while the alteration in DC trafficking and migration properties could participate in parasite dissemination. See Table 1.

2.5. Other Protozoan Parasites. There are several other species of protozoan parasites including Trichomonas sp., Giardia sp., Entamoeba sp., and Cryptosporidium sp. Unfortunately, these parasites have generally been poorly studied as far as their interactions with DC concern probably due to the fact that they have less morbidity and mortality among human populations. Nonetheless, recently it was shown that DCs incubated with Giardia lamblia live parasites or its extracts, display enhanced levels of CD40, CD80, and CD86 indicating their mature state. These cells produce small amounts of IL- 6 and TNF- $\alpha$ and no IL-10 or IL-12 is detected [94]. Importantly, coincubation of DC with parasite extracts and TLR ligands only enhance IL-10 production while markedly reducing IL-12 secretion and MHC-II, CD80, and CD86 levels. The mechanism of DC inhibition involves the activity of the phosphoinositide 3-Kinase (PI3K) since specific inhibition of this enzyme restores IL-12 production by these cells [94]. It is hypothesized that the ability of Giardia lamblia to inhibit IL-12 and enhance IL-10 production may contribute the maintenance of an antiinflammatory environment in the gut.

It is also known that lipopeptidophosphoglycan (LPPG) molecules from Entamoeba histolytica establish interactions with TLR2, and TLR4 leading to the release of IL-10, IL-12, and TNF- $\alpha$ [95]; and additionally, DNA from this parasite can be recognized by macrophages through TLR9 triggering TNF- $\alpha$ production [96]. With regard to DC, LPPG and also the parasite's surface Gal-lectin can activate these cells and induce their maturation along with IL-12 production, resulting in the induction of Th1-type responses [97, 98], although no findings regarding DC downregulation are available for this parasite.

TLR receptors are also involved in recognition of Cryptosporidium parvum and Trichomonas vaginalis but these interactions are normally between the parasites and host cells other than DC [99-102]. See Table 1.

\section{Helminth Parasites}

In marked contrast to protozoan parasites, helminthes are much larger hence they do not occupy intracellular spaces or are engulfed, having their interactions with immune system through the attachment of some immune cells to their surface or mainly by the recognition of diverse antigens released from the parasite. However, as for any parasite, their survival will depend on their capacity to cope with immune system's attacks. In this sense, interfering with DC activity is again one of the main ways to induce a permissive environment that allows their development inside the host. As noted earlier, during development and differentiation DC can be exposed to different stimuli which significantly influence their function and maturation, and helminthderived antigens are not the exception to this rule.

3.1. Nematodes. Semnani and coworkers demonstrated that when monocytes undergoing differentiation to DC engulfed B. malayi microfilariae antigens they display an inhibited production of IL-12p40, IL-12p70, and IL-10 in response to Staphylococcus aureus Cowan antigen (SAC) and SAC plus IFN- $\gamma$, suggesting an interference with TLR and IFN$\gamma$ signaling induced by this nematode [10]. Cell viability or expression of costimulatory molecules, including MHCI and MHC-II is not altered; however, DC exposed to these filarial antigens induce lymphocyte activation to a lesser degree than DC that were not exposed [10]. The same group recently reported a reduced TLR4, TLR3, and MyD88 mRNA expression in HMDC, as well as an impaired cytokine response to poly:IC and LPS upon exposure to live B. malayi microfilaria ( $\mathrm{mf})$ [103]. This indicates that this parasite can alter not just DC maturation but also their TLR responses affecting in turn $\mathrm{T}$ cell activation. In addition, MDC exposure to $\mathrm{mf}$ led to an enhancement in SOCS1 and SOCS3 mRNA transcripts [103], which are molecules known for their modulatory activity on cytokine production [104]. Furthermore, $\mathrm{mf}$ induces apoptosis in HMDC but not in macrophages [103]. Thus, the interaction of this helminth parasite and its antigens with DC clearly interferes with the function of these cells at different levels, from downregulating proinflammatory receptors to the induction of molecules involved in the suppression of cytokine production.

Another nematode, Nippostrongylus brasiliensis, secretes in vitro diverse glycoprotein named excretory-secretory products (NES). These antigens polarize the immune response towards a Th2 type without requiring live infection of the mice. Interestingly, BMDC pulsed with NES can upon transfer to naive recipients prime them to a Th2 response [105], suggesting that the Th2 driving properties of this extract occur through DC. In fact, NES upregulates DC markers associated with Th2 promotion, including CD86 and OX40L. In addition, the high levels of IL-12p70 induced by LPS are suppressed in DC that have been preincubated with NES [105]. This situation may contribute to the Th2 polarized response observed either during the infection with N. brasiliensis or in response to its antigens.

In in vivo studies, adult Ascaris suum high-molecularweight components (PI) inhibit MHC-II and costimulatory molecules in CD11c+ LN cells from OVA-PI-immunized mice compared with those immunized with OVA-CFA [9]. In line with an immature phenotype, these $\mathrm{CD} 11 \mathrm{c}+$ are poor inducers of proliferation, phenomen that is IL-10 dependent. Interestingly, OVA+PI was administered in CFA (Freund's complete adjuvant), suggesting that PI could inhibit the inflammatory effect of this adjuvant [9]. In addition, 
peritoneal CD11c+ cells recruited by pseudocoelomic fluid (PCF) from A. suum show basal levels in CD86 expression while BMDCs exposed to the same extract exhibit low increase in CD40 expression and are refractory to LPS stimulus, displaying once again an immature phenotype and a dose-dependent reduction in IL-12 production. [106]. Moreover, glycosphingolipids from A. suum containing phosphorylcholine (PC) downregulate IL-12p40 and TNF$\alpha$ secretion from DC, as well as a MHC-II, CD40, CD80, CD86, and CD54 in response to LPS. This modulation is due to native glycosphingolipids and PC-removed glycosphingolipids, suggesting that a molecule other than PC possesses immunomodulatory properties over DC, although this one has not yet been elucidated [107].

ES-62 is another molecule that contains PC; it is derived from excreted/secreted products of the nematode Acanthocheilonema vitae and has been shown to display a variety of immunomodulatory activities [108]. ES-62 exerts its immunomodulatory effects on an array of cells of the murine immune system, including macrophages and DC [108-110]. In particular, exposure of immature DC to ES62 lead to an unexpected increment in the expression of costimulatory molecules such as CD40, CD80, and CD86 and also, unlike other nematode molecules, ES-62 induce low but significant levels of IL-12p40 and TNF- $\alpha$ production in a MyD88-dependent manner. Interestingly when DC are stimulated with ES-62, there is an up-regulation of TLR4 expression; however, ES-62 had overall inhibitory effects on IL-12 and TNF- $\alpha$ production induced by TLR ligation. This suppressive effect is abrogated in TLR4 knockout but not in $\mathrm{C} 3 \mathrm{H} / \mathrm{HeJ}$ mice-derived $\mathrm{BMDC}$, suggesting the use of a coreceptor in this ES-62-TLR4-dependent signaling [108]. ES-62 is also capable of shifting BMDC into the "DC2" activation state [108]; when these DC2 cells present an ovoalbumin peptide to naïve CD4+ T cells from OVA TCR transgenic mice, an increase of IL-4 and a decrease of IFN$\gamma$ production by lymphocytes are observed. In addition, the switch to a Th2 response is not affected by differential regulation of CD80 or CD86 and it is achieved even in the presence of IL-12 [110]. Importantly, despite the fact that ES-62 is a high Th2 inductor, this molecule is incapable to overcome and bias the immune response to a Th2 type in the context of some inflammatory Th1 conditions such as $T$. gondii infection and O. volvulus synthetic protein $[111,112]$.

Other important data regarding DC activity modulation have come from studies with Heligmosomoides polygyrus excreted-secreted-derived products (HpES) and the adult worm homogenate $(\mathrm{AWH})$. None of these antigens induce BMDC maturation and IL-12, TNF- $\alpha$ or IL-10 is not found in culture supernatants [113]. Alike other helminthderived extracts, HpES alters TLR-induced cytokines and chemokines, since limited IL-12, TNF- $\alpha$, MCP-1, and RANTES production is elicited by stimulation with $\mathrm{CpG}$, LPS, and poly:IC. Interestingly, the production of the immunoregulatory cytokine IL-10 is also impaired. In addition, costimulatory molecules including CD40, CD86, and MHC-II but not CD80 are drastically downregulated also in response to TLR stimuli [113]. Even more, studies in vitro with a model of CD4+ OVA restricted activation, show that
DC treated with HpES not only attenuate but also IL-4 and IFN- $\gamma$ production by CD4+ T cells but enhance IL- 10 leading to Treg induction [113]. The findings for HpES correlate with an in vivo study where spleen DC isolated from $H$. polygyrus infected mice have an increased IL-10 production and a moderate up-regulation of CD80 and CD40. These $\mathrm{DC}$ are poor inducers of $\mathrm{CD} 4+\mathrm{T}$ cell proliferation and have the ability to decrease IFN- $\gamma$ and enhance IL- 4 production [114]. Thus, it is likely that the responses induced by $H$. polygyrus in DC, participate in providing a safer environment for parasite establishment and survival. Importantly, the impaired cytokine effect observed in DC exposed to $H$. polygyrus antigens is TLR2 and TLR4-independent [113] while data are available showing that these same receptors recognize molecules from other helminthes such as ES-62 from A. vitae $[11,15,108,115]$. These findings imply that the recognition and activity of helminth-derived molecules occurs through different receptors. This hypothesis has been further supported by a study that shows that calreticulin (CRT) present in H. polygyrus antigens lead to a Th2 response in vivo and this same molecule can be recognized by BMDC through Scavenger receptor A (SR-A) [116]. However; more studies are required to determine the phenotype that such recognition may confer to DC, and whether this phenotype is involved in the polarization toward Th2-type responses observed in the previous studies. Importantly, since CRT is preserved across the helminth parasites [86, $117-121]$, it is likely that this molecule might represent a potential pathogen-associated molecular pattern (PAMP) with a Th2-polarizing activity. See Table 2.

3.2. Trematodes. The most studied helminthes by far have been Schistosomes and in particular S. mansoni. They produce a great variety of glycosilated proteins and lipids to which mainly humoral immune responses are directed. In the case of $S$. mansoni, proteins, glycans and lipoconjugates can induce Th2-type responses. Several groups have shown that schistosome soluble egg antigens (SEA) contain molecules that drive the polarized CD4+ Th2 response [122, 123]. Many involved mechanisms have emerged and in this regard DC seem to have a critical role. For example, some glycans found in SEA such as core $\alpha$-3-fucose, $\beta 2$-xylose and Lewis $\mathrm{X}$, have been shown to play an important role in the changes observed in DC activity [18]. DC pulsed with fractions containing a motif of $\alpha 3$-fucosylation of a GlcNac or of $\beta$-xylosilated core sugar drive strong Th2-cell responses in mice [124]. When egg-derived glycoconjugates are captured, processed, and presented to naïve $\mathrm{T}$ lymphocytes by DC, the immune response is again skewed to a Th2-type response. Periodate treatment reverses this effect and CD1d is apparently crucial to this phenomenon, indicating that SEA glycolipids may be involved in the Th2 polarization by DC [124]. SEA activity on DC is even more profound, for instance; immature DC pulsed with this antigenic extract do not show an increase in expression of costimulatory molecules or cytokines while their LPS-induced activation, including expression of MHC-I and costimulatory molecules as well as IL-12 production is also suppressed. In addition, SEA inhibits the ability of $\mathrm{CpG}$, poly:IC and hyaluronic 
TABLE 2: Helminth products interactions and their regulatory effects on DC

\begin{tabular}{|c|c|c|c|c|c|c|c|}
\hline Parasite & Product & Putative DC Receptor & & Effect on DC & & $\begin{array}{l}\text { Effect on DC upon TLR } \\
\text { stimuli }\end{array}$ & Ref. \\
\hline \multicolumn{8}{|l|}{ Nematodes } \\
\hline \multirow[t]{7}{*}{ B. malayi } & Microfilarie alive & N.D. & & Immature & $\downarrow$ & $\begin{array}{l}\text { MIP-1, IL-12p70, IL-1 } \alpha \text {, } \\
\text { IFN- } \alpha, \text { IL-12p40, } \\
\text { MyD88, NFkB } \\
(\text { p50-p65) }\end{array}$ & \\
\hline & & & & TLR4,TLR3 & & & \\
\hline & & & $\downarrow$ & IL-8, RANTES, & & & {$[103]$} \\
\hline & & & $\uparrow$ & TNF- $\alpha$, IL- $1 \alpha$, IL- $1 \beta$, & & & \\
\hline & & & & SOCS1, SOCS3 & & & \\
\hline & & & & DC apoptosis & & & \\
\hline & Microfilarie Ag & N.D. & $\uparrow$ & CD80, CD40, MHCI & $\downarrow$ & $\begin{array}{l}\text { IL-12p40, } \\
\text { IL-12p70, IL-10 }\end{array}$ & {$[10]$} \\
\hline N. brasiliensis & NES & N.D. & $\uparrow$ & OX40L, CD86Th2* & $\downarrow$ & IL-12p70 & {$[105]$} \\
\hline \multirow[t]{5}{*}{ A. suum } & PI & N.D. & & Immature & $\downarrow$ & IL-12p40 & {$[9]$} \\
\hline & PCF & N.D. & & Immature & & IL-12, & \\
\hline & & & & & $\downarrow$ & $\mathrm{CD} 40, \mathrm{CD} 86$ & {$[106]$} \\
\hline & Glycosphingolipids & N.D. & & Immature & $\downarrow$ & IL-12p40, & \\
\hline & $\begin{array}{c}\text { (PC cointained but PC } \\
\text { independent })\end{array}$ & & & & & $\mathrm{TNF} \alpha, \mathrm{CD} 86$ & {$[107]$} \\
\hline \multirow[t]{3}{*}{ A. vitae } & ES-62 (PC contain) & TLR4 & & TLR4, CD80 * & & IL-12, TNF $\alpha$ & \\
\hline & & & $\uparrow$ & $\begin{array}{l}\text { IL-12p40 (low), } \\
\text { TNF } \alpha \text { (low) }\end{array}$ & $\downarrow \uparrow$ & IL-10 & \\
\hline & & & & Th2* & & & {$[108,110]$} \\
\hline \multirow[t]{4}{*}{ H. polygyrus } & ES & N.D. & & Immature & & IL-12, TNF $\alpha$ & \\
\hline & & & & IFN $\gamma^{*}, \mathrm{IL}-4^{*}$ & & MCP1, RANTES, & {$[113,114]$} \\
\hline & & & $\downarrow \uparrow$ & IL-10(Treg)* & $\downarrow$ & MHCII, CD40, CD86 & \\
\hline & Calreticulin & SR-A & & N.D. & & N.D. & {$[116]$} \\
\hline \multicolumn{8}{|l|}{ Trematodes } \\
\hline \multirow[t]{7}{*}{ S. mansoni } & SEA & DC-SIGN, MR, MGL & & Immature & & & \\
\hline & & & $\uparrow$ & $\begin{array}{l}\text { DC-SIGN,MR, } \\
\text { DCIR, MGL, }\end{array}$ & $\downarrow$ & $\begin{array}{l}\text { IL-12p 40,IL-12p70, } \\
\text { TNF } \alpha, \text { IL-6, MHCII, } \\
\text { CD80, CD } 86\end{array}$ & $\begin{array}{c}{[18,124-} \\
126]\end{array}$ \\
\hline & & & & Jagged 2,TLR4 & & & \\
\hline & & & & Th2* & $\uparrow$ & IL-10 & \\
\hline & LNFPIII & TLR4 & & Immature & & N.D. & \\
\hline & & & $\uparrow$ & $\begin{array}{l}\text { ERK, NFkB, } \\
\text { Th2* }\end{array}$ & & & {$[15,128]$} \\
\hline & Lysophospahtidyl-serine & TLR2 & $\uparrow$ & $\begin{array}{l}\text { ERK, c-fos, } \\
\text { Th2*, Treg* }\end{array}$ & $\downarrow$ & $\operatorname{IFN} \gamma^{*}$ & {$[11,115]$} \\
\hline \multicolumn{8}{|l|}{ Cestodes } \\
\hline E. granulosus & $\mathrm{AgB}$ & N.D. & $\uparrow$ & $\begin{array}{l}\text { IRAKp, NF-kB, } \\
\text { TNF- } \alpha^{\text {low }} \\
\text { IL- } 10^{\text {low }}, \text { IL-6 } 6^{\text {low }} \\
\text { Th2* }\end{array}$ & $\downarrow$ & $\begin{array}{l}\text { IL-12p70, } \\
\text { TNF } \alpha, \text { IL-6, } \\
\text { IL-10, HLA-DR } \\
\text { CD80, CD86 }\end{array}$ & {$[14]$} \\
\hline T. crassiceps & $\begin{array}{c}\text { ES } \\
\text { (carbohydrate } \\
\text { dependent) }\end{array}$ & N.D. & $\uparrow$ & $\begin{array}{l}\text { MHCII, } \\
\text { Th2* }\end{array}$ & $\downarrow$ & $\begin{array}{l}\text { IL-15, IL-12p40, } \\
\text { IL-12p70, TNF } \alpha, \text { CD } 80, \\
\text { CD } 86, \text { CD } 40, \text { CCR7, } \\
\text { IFN } \gamma^{*}\end{array}$ & \\
\hline
\end{tabular}

ๆ Involved in modulatory effects on DC.

* T cell response. 
acid (HA) to induce production of IL-12 and up-regulation of MHC-II, CD80, and CD86 on DC. Even though IL10 production is augmented in the presence of SEA, not all the SEA effects on DC depend on this cytokine [125, 126]. SEA also suppresses the LPS-induced expression of 46 genes in DC, many of which are proinflammatory, and it also prevents the LPS-induced downregulation of 37 genes that may be involved in the changes observed in DC function upon SEA exposure [125]. Thus, SEA appears to have a profound effect on TLR ligand-induced DC maturation/activation, suppressing inflammatory events associated with development of Th1-type responses. SEA probably also affects the antigen-processing pathway as DC exposed to SEA show a difference in antigen processing by segregating SEA to a different compartment when compared with a bacterial antigen (form Propionibacterium acnes). Since these two antigens are handled very differently, this could explain the contrasting responses they induce in these cells [125].

In contrast with other helminthes, molecules from $S$. mansoni have been more fully characterized and important data regarding them have been reported (reviewed in [127]). Lipids from S. mansoni, particularly those containing phosphatidylserine, act as Th2-promoting factors through the blockade of IL-12 production by DC while promoting the development of IL-10-producing Treg cells [11]. It has been shown that these molecules can be recognized through TLR2 and interestingly antibody blockade of TLR2 diminishes their ability to induce a Treg response but not the Th2 polarization [11], suggesting another pathway and probably another receptor involved in the DC Th2-driving activity. New data show that these lysophosphatidylserine molecules can increase ERK but not p38 phosphorylation on DC and induce an up-regulation in c-Fos transcription; in contrast, Delta4 (Notch ligand) is strongly downregulated. These combined factors may ultimately lead to the development of a Th2 response [115]. According to this report, the glycoconjugate LNFPIII (also S. mansoni egg derived) leads to ERK1/2 phosphorylation but not p38 in DC and posses Th2-biasing ability through the induction of DC2 in a TLR4-dependent manner [15]. NF-kB alternative activation through p105 degradation is necessary for these LNFPIIImediated effects [128]. However, recent evidence show that the Th2 polarizing effect of SEA is maintained in TLR2 or TLR4 knockout mice and MyD88 is also unnecessary [126]. This finding may rule out the participation of TLR in the effects induced by the molecules present in SEA. These data also open the possibility of the involvement of many others receptors such as CLRs, other lectin or Notch receptors in the recognition and modulatory activity of the S. mansoni antigens over DC. According to this idea, DC can recognize carbohydrates present in SEA through CLRs like mannose receptor (MR), macrophage galactose-type lectin (MGL) and DC-SIGN while exposure of the same cells to SEA can upregulate the expression of these same CLRs and the one of DC-immunoreceptor (DCIR) [18]. In addition, there is recent evidence showing that DC may recognize helminth products through molecule-grabbing nonintegrin receptor 1 (SINGR1). This CLR has been shown to bind SEA in vitro, however studies using SINGR1 knock-out mice have not found any significant differences in the kinetic of immune responses after S. mansoni infection [129]. SEA can also enhance expression of Jagged 2 in DC, but downregulation of Jagged 2 using RNAi does not affect the ability to prime Th2 responses [130]. This situation could reflect the fact that different receptors present in DC may have similar effects [131]. Due to the diverse molecules found in SEA and indeed in other different parasite products (crude extracts or excreted/secreted products), many receptors could be involved in the recognition of the different molecules present in these extracts, in such a way, that the lack of one receptor might not affect the immune response induced by these antigens. Therefore, helminth parasites probably posses redundant molecules to escape from immunity, unfortunately so far, only few of them have been characterized and their interaction with DC is still far from being understood. Even when CLRs or Notch receptors could be involved in DC recognition of helminth products, more studies are necessary to establish whether these interactions participate in the changes observed in these cells and in turn in the systemic effects they induce. See Table 2.

3.3. Cestodes. Studies regarding the interaction of this class of helminthes and DC are far less extensive when compared with trematodes and nematodes. Nevertheless, most of them point to similar pathways of alteration of DC function by cestode-derived molecules. For example, Rigano and colleagues demonstrated that Echinococcus granulosus hydatid cyst antigens affect DC in different stages of maturation [14]. Purified antigen B (AgB) and sheep hydatid fluid (SHF) affect host DC differentiation from monocyte precursors by reducing the number of cells that differentiate into immature DCs (iDCs) inhibiting as well the up-regulation of CD1a while increasing CD86 expression. When these cells are stimulated with LPS, there is a significantly lower expression of CD80, CD86, and HLA-DR and lower quantities of TNF- $\alpha$ and IL-12p70. In addition, E. granulosus antigens interfere in the maturation process of these iDCs, inducing only a slight up-regulation of CD80, CD86 and a small TNF- $\alpha$, IL-10, and IL-6 production ablating IL-12p70 completely. In response to LPS, DC previously exposed to E. granulosus antigens, express fewer CD80 and CD86 molecules and show reduced TNF- $\alpha$ and IL-12p70 production. When DC matured in the presence of E. granulosus antigens are used as APCs, the majority of naive $\mathrm{T}$ lymphocytes differentiate into IL4-producing cells, suggesting the potential of these antigens to skew the response to a Th2 [14]. However, neither the receptors on DC nor the type of molecules derived from Echinoccocus that are involved in DC modulation has been identified in this model.

Another cestode that has recently been proved to interfere with DC activity is Taenia crassiceps. Carbohydrates present in soluble antigens of this parasite are responsible for Th2 polarization in vivo [132] and induction of myeloid suppressor innate cells [133]. We have found that DC exposure to excreted/secreted products of high molecular weight from $T$. crassiceps metacestodes (TcES) induce an increment in MHCII expression but not in the costimulatory 
molecules CD80, CD86 or CD40 or in cytokine production. In line with findings for other helminthes, DC exposure to TcES results in an abrogated response to TLR ligands such as CpG, LPS and Toxoplasma soluble antigens; these include the inhibition of IL-15, IL12p40, IL12p70, TNF$\alpha$ secretion and costimulatory molecules but no MHC-II expression. In addition, the chemokine receptor CCR7 is also downregulated, suggesting the reduced ability of DC to migrate to rich $\mathrm{T}$ cell areas as another possible mechanism used by $T$. crassiceps to evade the immune response. When TcES-stimulated DC are tested in an allostimulation assay, these cells are weak inducers of $\mathrm{T}$ cell proliferation and the presence of TcES also downregulate the strong proliferation expected by addition of LPS or CPG. Of particular interest is that periodate-treated TcES are unable to inhibit the production of proinflammatory cytokines elicited by different TLR ligands and in the same way, carbohydrates in TcES are necessary to polarize the immune response towards a Th2 type in a CD4+ OVA transgenic model. This situation opens the possibility for a role of carbohydrate receptors in the modulation of DC function by $T$. crassiceps-antigens (C, Terrazas, manuscript under review). Interestingly, the limited responses observed in DC of BALB/c mice (a susceptible strain for $T$. crassiceps infection) upon TLR stimulation is not observed when DC derived from the resistant mice C57Bl/6 are exposed to TcES [134], indicating that modulation of DC response by T. crassiceps-products is a key element in the outcome of this infection. See Table 2.

\section{Parasites and the Interference with DC Function: Is There a Common Pathway in a Common Strategy?}

The evidence discussed in this review clearly show that by targeting the principal sentinels and directors of the immune system, DC, parasites actively evade immune attack. DC pleiotropy allows protozoan and helminth parasites to interfere with different aspects of the immune response. In most cases, either protozoan or helminth parasites, are able to impair the maturation process and the proinflammatory cytokine production of DC $[9,14,19,52,66,113]$, but other effects like a modified migration or an inability to fully differentiate are also found on DC exposed to these parasites or their products $[14,28,55,92]$. The consequences of these different effects on DC function are diverse, but ultimately it is believed that they provide a less aggressive environment for parasite development inside their host. Several findings indicate the recognition of parasites and their molecules through TLRs [11, 36, 65, 108]. However, it has been more complicated to define whether these interactions lead to the altered phenotype and function that is observed in DC exposed to protozoan and helminth parasites. For the protozoan parasites, most data indicate that recognition and signaling of the whole parasites or their products through TLRs trigger activation pathways in DC that ultimately confers resistance against infection $[36,75,82]$. However, it is important to point out that some of the same molecules that act as TLR ligands and induce a protective response, can also interfere with the DC function by inhibiting their maturation and production of the proinflammatory cytokines associated with parasite clearance $[28,37,51,62]$. The mechanisms involved in DC "inactivation" are far from being completely understood. One possible explanation for this is the recognition of protozoan-derived molecules by other receptors than TLRs that in turn might interfere with TLR function. According to this rationale, in the last years new evidence has implicated CLRs as important players in intracellular signalling rather than only phagocyte receptors and more importantly, these receptors are also capable of inhibit TLR-mediated signalling [131]. Of special interest is to note, that impairment of TLR-induced response has turned out to be a common and a main feature in the modulation of DC induced not just by protozoan, but also by helminth parasites $[66,87,103,113]$. Interference with TLR signalling may explain most of the downregulatory effects that these parasites have on DC, since MyD88-dependent pathways are involved in DC maturation and secretion of key cytokines such as IL-12 [61, 135]. However, evidence shows that other receptors and hence other signalling pathways may be involved in DC downregulation. An example of this is the phenomenon of "DC-paralysis" observed after the peak of IL-12 production in response to T. gondii parasites or its antigens. This is achieved by the parasite-induced production of lipoxin $\mathrm{A}_{4}\left(\mathrm{LXA}_{4}\right)[85,136]$, which in turn is recognized by the FRPL-1 or AhR receptors on DC [16], triggering SOCS2 and turning off IL-12 production [137]. Likely, similar mechanisms could promote the low response observed on DC exposed to other protozoa and even helminthes since B. malayi microfilariae can also up-regulate expression of SOCS1 and SOCS3 [103]. Alternatively, TLR-stimulation could trigger different responses from DC, probably by becoming tolerogenic [30] or exhausted [84, 138, 139] (Figure 1).

For helminthes, the interaction with TLRs on DC lead, in general, to a "immature state" characterized by an absence or a moderate expression of costimulatory molecules together with no proinflammatory cytokines secretion, features that in turn seem to induce the development of a Th2 immune response [140]. Once again, the exact mechanism implicated in DC proinflammatory cytokine downregulation in response to TLR stimulus and the signals elicited by helminth products that condition these same cells to induce a Th2 response still remain unclear $[140,141]$. Interestingly, not all the costimulatory molecules are downregulated in DC exposed to helminth products. For OX40L, a molecule important for an optimal Th2 response, there is an upregulation in presence of some helminth products [105, 142]. In this regard, it would be important to determine if other molecules can be expressed selectively after helminth antigen recognition and this knowledge could lead to a definition of a truly Th2 polarizing DC phenotype. Other features have been investigated in an effort to define the phenotype and characteristics of helminth pulsed DC. While most of the evidence shows these DC are in an "immature state", recent data indicate that SEA can induce phagosome maturation, a characteristic that is associated with DC maturation. In this 


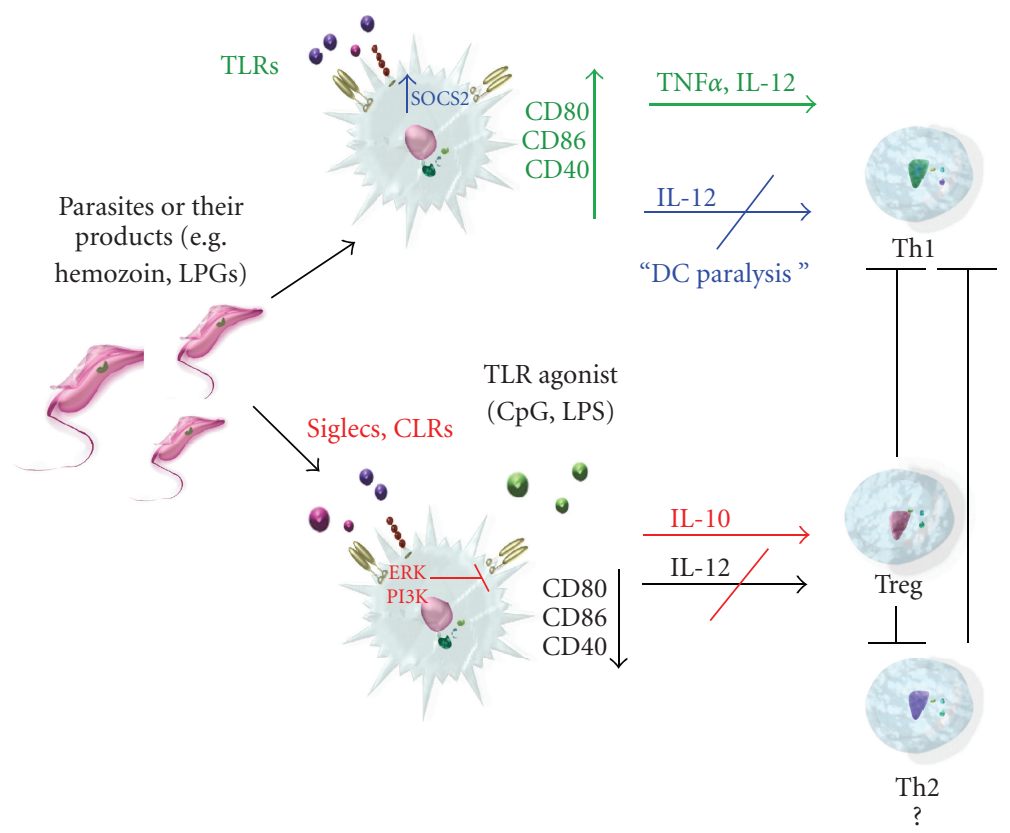

FIgure 1: Overview to protozoan and DC interactions. Protozoan parasites and their products interact with TLRs on DC leading to their activation and release of proinflammatory cytokines and up-regulation of costimulatory molecules promoting a Th1 responses and the control of the infection. However, in some cases ( $T$. gondii infection), this response can be later impaired by the same parasites through mechanisms that involve enhancement of SOCS proteins expression and downregulation of IL-12 production. In addition, interactions of parasite molecules with Siglecs and CLRs may be responsible of maintaining DC in an immature state and refractory to TLR stimuli, diminishing their proinflammatory response likely by using ERK and PI3K-dependent pathways. These DC may lead to activation of Treg responses that presumably favour parasite survival.

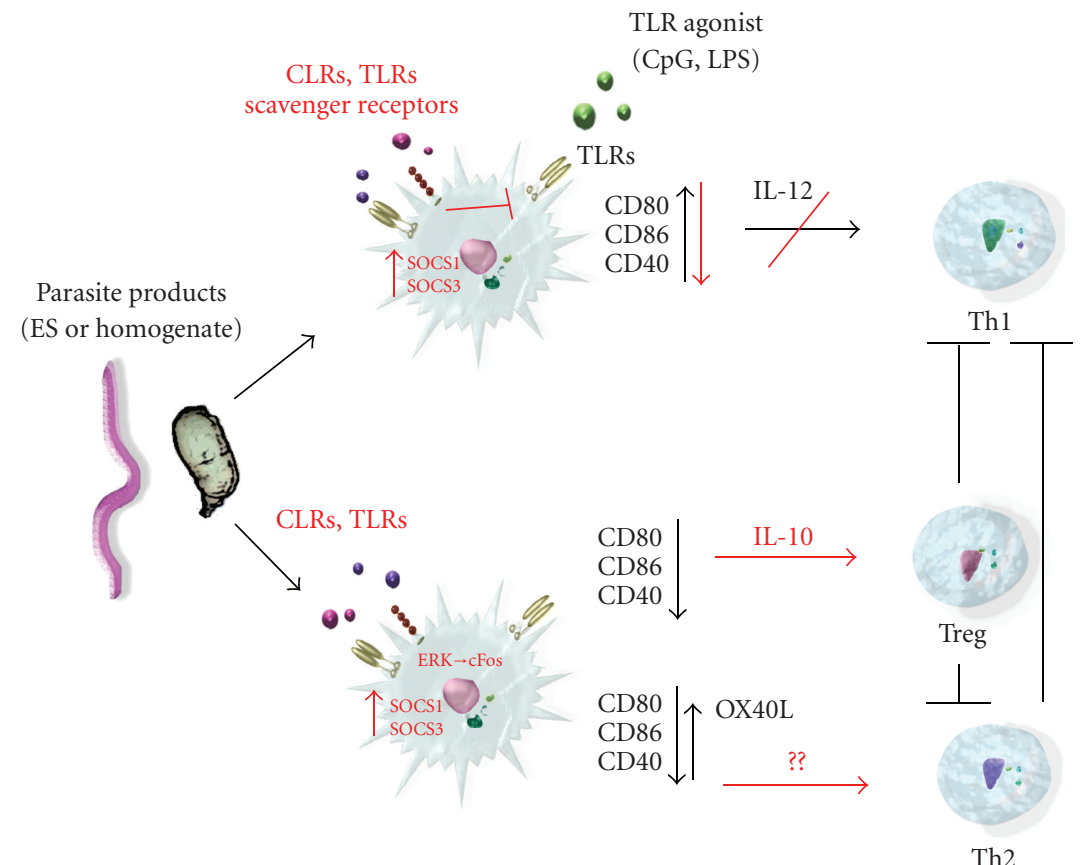

FIgure 2: Overview to helminth and DC interactions. Helminth products are recognized by receptors such as TLRs, CLRs or Scavenger receptors. These cells remain in an immature state and unresponsive to further TLR stimuli probably due to interaction and signalling of parasite molecules through CLRs. Signalling pathways that implicate ERK phosphorylation, c-Fos up-regulation and expression of SOCS proteins may play a role in downregulation of DC responses particularly by suppressing IL-12 production. Once again, interactions of helminth molecules with CLRs but also with TLRs may be involved in these inhibitory effects. Finally, these helminth-conditioned DC induce a Th2 or Treg lymphocyte responses. 
study, LPS and SEA-stimulated DC have similar phagosome acidification and proteolytic activity and this effect is MyD88 independent disregarding the activity by most TLRs [143]. Thus DC exposed to helminth products could exhibit an immature phenotype along with some features of a mature phenotype (Figure 2).

As mentioned earlier in this review, ligation of some CLRs might lead to the impairment of TLR-mediated signalling [131]. For instance, ligation of DC-SIGN on the DC can preferentially induce IL-10 production upon LPS addition [144] and the interaction of this receptor with pathogens such as Mycobacterium sp., HIV-1 and Candida albicans, affects TLR-4-mediated immune responses by the same cells $[145,146]$. Interestingly, DC-SIGN binds SEA and this antigen extract and other glycoconjugates derived from S. mansoni, can alter DC responses after TLR-stimulation [18].

Other lectin receptors might also posses the ability to interfere with TLR-induced response in DC. Recently, it has been shown that sialylated structures from $T$. cruzi bind the inhibitory lectin, Siglec-E. Of special interest, is that this interaction likely account for the suppression of LPS-induced IL-12 production and the enhanced levels of IL-10 observed in DC exposed to T. cruzi parasites [17]. Supporting this idea, other studies have shown a downregulation of immune cells responses after ligation of Siglecs [147, 148].

Signalling pathways involving activation of the kinases ERK and PI3K have been implicated in the negative regulation of DC maturation and IL-12 synthesis as well as in the enhanced production of IL-10. It is believed that pathogens use these signals to preferentially evoke Th2type immune responses or at least impaired their opposing party $[141,144,149-151]$. In this regard, it is important to note, that among protozoan and helminth parasites, activation of ERK and PIK3 seem to play indeed, a main role in the interference of DC function. Different examples of ERK activation implicated in impaired DC maturation, downregulation of IL-12 production or polarization of the immune response to Th2 have been reported for both types of parasites $[26,49,115,128]$, whereas the protozoos $G$. lamblia and $L$. major can also inhibit IL-12 synthesis in a PI3K-dependent pathway $[94,151]$. Interestingly, pathways ERK and PI3K-dependent can be activated by engagement of CLRs [144, 152],

We believe that interaction of protozoan and helminth molecules with CLRs and probably other lectin receptors, along with the consequent activation of ERK and PI3Kdependent pathways, are key events that might determine the way a DC respond, either to direct parasite stimuli or to heterologous TLR ligands. This mechanism may explain, the induced immature phenotypes observed in DC exposed to these parasites and their products as well as the decreased proinflammatory cytokine production (IL-12 mainly). The enhanced IL-10 synthesis and Treg or Th2 polarization activity of DC exposed to protozoan and helminthes antigens, may also be a consequence of such interactions. Therefore, even when more studies are necessary to determine the exact mechanisms involved in downregulation of DC function by parasites, after all, there is maybe a common pathway that helminth and protozoan parasites use to achieve it (Figures 1 and 2).

\section{Concluding Remarks}

During evolution, parasites have developed several sophisticated strategies in order to avoid or deal with the attacks of immune system. These studies have shown that interfering with the activity of DC can be one of the most effective ways to induce a safer environment to parasite development. Interestingly, despite the phylogenic distance between protozoa and helminthes and even among helminthes, there seems to be a remarkable similarity in the way all these parasites modulate DC responses. Interaction with different receptors, particularly CLRs, may induce the downregulation in DC function although several other molecules like, Scavenger, lectins or G-coupled signaling receptors could also be involved. Understanding the different mechanisms that these parasites use to interfere with DC will certainly answer important questions that will increase our understanding of these pleiotropic cells and help us to design targeted therapeutic strategies based on this knowledge.

\section{Acknowledgments}

The authors would like to thank Dr. Jose Ignacio Saldaña (Imperial College London) for his helpful comments to this article. CONACYT-Mexico supported $\mathrm{PhD}$ fellowship for the first author and this review is a requirement to obtain his degree in Biomedical Sciences, UNAM. This work was supported by grant 60956-M from CONACYT-México.

\section{References}

[1] A. Lanzavecchia and F. Sallusto, "The instructive role of dendritic cells on $\mathrm{T}$ cell responses: lineages, plasticity and kinetics," Current Opinion in Immunology, vol. 13, no. 3, pp. 291-298, 2001.

[2] J. Banchereau and R. M. Steinman, "Dendritic cells and the control of immunity," Nature, vol. 392, no. 6673, pp. 245252, 1998.

[3] J. Banchereau, F. Briere, C. Caux, et al., "Immunobiology of dendritic cells," Annual Review of Immunology, vol. 18, pp. 767-811, 2000.

[4] P. Guermonprez, J. Valladeau, L. Zitvogel, C. Thery, and S. Amigorena, "Antigen presentation and T cell stimulation by dendritic cells," Annual Review of Immunology, vol. 20, pp. 621-667, 2002.

[5] A. Lanzavecchia and F. Sallusto, "Dynamics of T lymphocyte responses: intermediates, effectors, and memory cells," Science, vol. 290, no. 5489, pp. 92-97, 2000.

[6] M. N. Wykes, X. Q. Liu, L. Beattie, et al., "Plasmodium strain determines dendritic cell function essential for survival from malaria," PLoS Pathogens, vol. 3, no. 7, article e96, 2007.

[7] L. Xin, Y. Li, and L. Soong, "Role of interleukin- $1 \beta$ in activating the CD11chigh CD45RB- dendritic cell subset and priming Leishmania amazonensis- specific $\mathrm{CD} 4^{+} \mathrm{T}$ cells in vitro and in vivo," Infection and Immunity, vol. 75, no. 10, pp. 5018-5026, 2007. 
[8] M. Pepper, F. Dzierszinski, E. Wilson, et al., "Plasmacytoid dendritic cells are activated by Toxoplasma gondii to present antigen and produce cytokines," Journal of Immunology, vol. 180, no. 9, pp. 6229-6236, 2008.

[9] S. R. Silva, J. F. Jacysyn, M. S. Macedo, and E. L. FaquinMauro, "Immunosuppressive components of Ascaris suum down-regulate expression of costimulatory molecules and function of antigen-presenting cells via an IL-10-mediated mechanism," European Journal of Immunology, vol. 36, no. 12, pp. 3227-3237, 2006.

[10] R. T. Semnani, H. Sabzevari, R. Iyer, and T. B. Nutman, "Filarial antigens impair the function of human dendritic cells during differentiation," Infection and Immunity, vol. 69, no. 9, pp. 5813-5822, 2001.

[11] D. van der Kleij, E. Latz, J. F. Brouwers, et al., "A novel host-parasite lipid cross-talk. Schistosomal lysophosphatidylserine activates Toll-like receptor 2 and affects immune polarization," Journal of Biological Chemistry, vol. 277, no. 50, pp. 48122-48129, 2002.

[12] K. Jangpatarapongsa, P. Chootong, J. Sattabongkot, et al., "Plasmodium vivax parasites alter the balance of myeloid and plasmacytoid dendritic cells and the induction of regulatory T cells," European Journal of Immunology, vol. 38, no. 10, pp. 2697-2705, 2008.

[13] A.-M. Sponaas, E. T. Cadman, C. Voisine, et al., "Malaria infection changes the ability of splenic dendritic cell populations to stimulate antigen-specific T cells," Journal of Experimental Medicine, vol. 203, no. 6, pp. 1427-1433, 2006.

[14] R. Rigano, B. Buttari, E. Profumo, et al., "Echinococcus granulosus antigen B impairs human dendritic cell differentiation and polarizes immature dendritic cell maturation towards a Th2 cell response," Infection and Immunity, vol. 75, no. 4, pp. 1667-1678, 2007.

[15] P. G. Thomas, M. R. Carter, O. Atochina, et al., "Maturation of dendritic cell 2 phenotype by a helminth glycan uses a Toll-like receptor 4-dependent mechanism," Journal of Immunology, vol. 171, no. 11, pp. 5837-5841, 2003.

[16] F. S. Machado, J. E. Johndrow, L. Esper, et al., "Antiinflammatory actions of lipoxin A4 and aspirin-triggered lipoxin are SOCS-2 dependent," Nature Medicine, vol. 12, no. 3, pp. 330-334, 2006

[17] H. Erdmann, C. Steeg, F. Koch-Nolte, B. Fleischer, and T. Jacobs, "Sialylated ligands on pathogenic Trypanosoma cruzi interact with Siglec-E (sialic acid-binding Ig-like lectin-E)," Cellular Microbiology, vol. 11, no. 11, pp. 1600-1611, 2009.

[18] E. van Liempt, S. J. van Vliet, A. Engering, et al., "Schistosoma mansoni soluble egg antigens are internalized by human dendritic cells through multiple C-type lectins and suppress TLR-induced dendritic cell activation," Molecular Immunology, vol. 44, no. 10, pp. 2605-2615, 2007.

[19] O. R. Millington, C. Di Lorenzo, R. S. Phillips, P. Garside, and J. M. Brewer, "Suppression of adaptive immunity to heterologous antigens during Plasmodium infection through hemozoin-induced failure of dendritic cell function," Journal of Biology, vol. 5, article 5, 2006.

[20] B. C. Urban, D. J. P. Ferguson, A. Pain, et al., "Plasmodium falciparuminfected erythrocytes modulate the maturation of dendritic cells," Nature, vol. 400, no. 6739, pp. 73-77, 1999.

[21] J. A. Perry, C. S. Olver, R. C. Burnett, and A. C. Avery, "Cutting edge: the acquisition of TLR tolerance during malaria infection impacts $\mathrm{T}$ cell activation," Journal of Immunology, vol. 174, no. 10, pp. 5921-5925, 2005.

[22] M. N. Wykes, X. Q. Liu, S. Jiang, C. Hirunpetcharat, and M. F. Good, "Systemic tumor necrosis factor generated during lethal Plasmodium infections impairs dendritic cell function," Journal of Immunology, vol. 179, no. 6, pp. 39823987, 2007.

[23] C. Ocana-Morgner, K. A. Wong, and A. Rodriguez, "Interactions between dendritic cells and $\mathrm{CD}^{+} \mathrm{T}$ cells during Plasmodium infection," Malaria Journal, vol. 7, article 88, 2008.

[24] C. Ocana-Morgner, M. M. Mota, and A. Rodriguez, "Malaria blood stage suppression of liver stage immunity by dendritic cells," Journal of Experimental Medicine, vol. 197, no. 2, pp. 143-151, 2003.

[25] J. Langhorne, S. J. Quin, and L. A. Sanni, "Mouse models of blood-stage malaria infections: immune responses and cytokines involved in protection and pathology," Chemical Immunology, vol. 80, pp. 204-228, 2002.

[26] P. Mukherjee and V. S. Chauhan, "Plasmodium falciparumfree merozoites and infected RBCs distinctly affect soluble CD40 ligand-mediated maturation of immature monocytederived dendritic cells," Journal of Leukocyte Biology, vol. 84, no. 1, pp. 244-254, 2008.

[27] J. M. Orengo, K. A. Wong, C. Ocana-Morgner, and A. Rodriguez, "A Plasmodium yoelii soluble factor inhibits the phenotypic maturation of dendritic cells," Malaria Journal, vol. 7, article 254, 2008.

[28] O. A. Skorokhod, M. Alessio, B. Mordmuller, P. Arese, and E. Schwarzer, "Hemozoin (malarial pigment) inhibits differentiation and maturation of human monocyte-derived dendritic cells: a peroxisome proliferator-activated receptor$\gamma$-mediated effect," Journal of Immunology, vol. 173, no. 6, pp. 4066-4074, 2004.

[29] O. Skorokhod, E. Schwarzer, T. Grune, and P. Arese, "Role of 4-hydroxynonenal in the hemozoin-mediated inhibition of differentiation of human monocytes to dendritic cells induced by GM-CSF/IL-4," BioFactors, vol. 24, no. 1-4, pp. 283-289, 2005.

[30] H. Hisaeda, K. Tetsutani, T. Imai, et al., "Malaria parasites require TLR9 signaling for immune evasion by activating regulatory T cells," Journal of Immunology, vol. 180, no. 4, pp. 2496-2503, 2008.

[31] K. A. Wong and A. Rodriguez, "Plasmodium infection and endotoxic shock induce the expansion of regulatory dendritic cells," Journal of Immunology, vol. 180, no. 2, pp. 716-726, 2008.

[32] P. C. Bull and K. Marsh, "The role of antibodies to Plasmodium falciparum-infected-erythrocyte surface antigens in naturally acquired immunity to malaria," Trends in Microbiology, vol. 10, no. 2, pp. 55-58, 2002.

[33] D. I. Baruch, J. A. Gormley, C. Ma, R. J. Howard, and B. L. Pasloske, "Plasmodium falciparum erythrocyte membrane protein 1 is a parasitized erythrocyte receptor for adherence to CD36, thrombospondin, and intercellular adhesion molecule 1," Proceedings of the National Academy of Sciences of the United States of America, vol. 93, no. 8, pp. 3497-3502, 1996.

[34] M. Fried and P. E. Duffy, "Adherence of Plasmodium falciparum to chondroitin sulfate A in the human placenta," Science, vol. 272, no. 5267, pp. 1502-1504, 1996.

[35] S. R. Elliott, T. P. Spurck, J. M. Dodin, et al., "Inhibition of dendritic cell maturation by malaria is dose dependent and does not require Plasmodium falciparum erythrocyte membrane protein 1," Infection and Immunity, vol. 75, no. 7, pp. 3621-3632, 2007.

[36] C. Coban, K. J. Ishii, T. Kawai, et al., “Toll-like receptor 9 mediates innate immune activation by the malaria pigment 
hemozoin," Journal of Experimental Medicine, vol. 201, no. 1, pp. 19-25, 2005.

[37] S. Pichyangkul, K. Yongvanitchit, U. Kum-arb, et al., "Malaria blood stage parasites activate human plasmacytoid dendritic cells and murine dendritic cells through a Toll-like receptor 9-dependent pathway," Journal of Immunology, vol. 172, no. 8, pp. 4926-4933, 2004.

[38] J. Zhu, G. Krishnegowda, and D. C. Gowda, "Induction of proinflammatory responses in macrophages by the glycosylphosphatidylinositols of Plasmodium falciparum: the requirement of extracellular signal-regulated kinase, p38, cJun N-terminal kinase and NF- $\kappa \mathrm{B}$ pathways for the expression of proinflammatory cytokines and nitric oxide," Journal of Biological Chemistry, vol. 280, no. 9, pp. 8617-8627, 2005.

[39] P. Parroche, F. N. Lauw, N. Goutagny, et al., "Malaria hemozoin is immunologically inert but radically enhances innate responses by presenting malaria DNA to Toll-like receptor 9," Proceedings of the National Academy of Sciences of the United States of America, vol. 104, no. 6, pp. 1919-1924, 2007.

[40] S. L. Reiner and R. M. Locksley, "The regulation of immunity to Leishmania major," Annual Review of Immunology, vol. 13, pp. 151-177, 1995.

[41] F. Mattner, J. Magram, J. Ferrante, et al., "Genetically resistant mice lacking interleukin-12 are susceptible to infection with Leishmania major and mount a polarized Th2 cell response," European Journal of Immunology, vol. 26, no. 7, pp. 15531559, 1996.

[42] H. Chakir, A. Campos-Neto, M. Mojibian, and J. R. Webb, "IL-12R $\beta 2$-deficient mice of a genetically resistant background are susceptible to Leishmania major infection and develop a parasite-specific Th2 immune response," Microbes and Infection, vol. 5, no. 4, pp. 241-249, 2003.

[43] K. Suzue, S. Kobayashi, T. Takeuchi, M. Suzuki, and S. Koyasu, "Critical role of dendritic cells in determining the Th 1/Th2 balance upon Leishmania major infection," International Immunology, vol. 20, no. 3, pp. 337-343, 2008.

[44] E. von Stebut, Y. Belkaid, B. V. Nguyen, M. Cushing, D. L. Sacks, and M. C. Udey, "Leishmania major-infected murine Langerhans cell-like dendritic cells from susceptible mice release IL-12 after infection and vaccinate against experimental cutaneous Leishmaniasis," European Journal of Immunology, vol. 30, no. 12, pp. 3498-3506, 2000.

[45] H. Qi, V. Popov, and L. Soong, "Leishmania amazonensisdendritic cell interactions in vitro and the priming of parasite-specific CD4 ${ }^{+} \mathrm{T}$ cells in vivo," Journal of Immunology, vol. 167, no. 8, pp. 4534-4542, 2001.

[46] P. Konecny, A. J. Stagg, H. Jebbari, N. English, R. N. Davidson, and S. C. Knight, "Murine dendritic cells internalize Leishmania major promastigotes, produce IL-12 p40 and stimulate primary T cell proliferation in vitro," European Journal of Immunology, vol. 29, no. 6, pp. 1803-1811, 1999.

[47] E. von Stebut, Y. Belkaid, T. Jakob, D. L. Sacks, and M. C. Udey, "Uptake of Leishmania major amastigotes results in activation and interleukin 12 release from murine skinderived dendritic cells: implications for the initiation of antiLeishmania immunity," Journal of Experimental Medicine, vol. 188, no. 8, pp. 1547-1552, 1998.

[48] C. Favali, N. Tavares, J. Clarencio, A. Barral, M. BarralNetto, and C. Brodskyn, "Leishmania amazonensis infection impairs differentiation and function of human dendritic cells," Journal of Leukocyte Biology, vol. 82, no. 6, pp. 14011406, 2007.

[49] P. M. Boggiatto, F. Jie, M. Ghosh, et al., "Altered dendritic cell phenotype in response to Leishmania amazonensis amastigote infection is mediated by MAP kinase, ERK," American Journal of Pathology, vol. 174, no. 5, pp. 1818-1826, 2009.

[50] C. L. Bennett, A. Misslitz, L. Colledge, T. Aebischer, and C. C. Blackburn, "Silent infection of bone marrow-derived dendritic cells by Leishmania mexicana amastigotes," European Journal of Immunology, vol. 31, no. 3, pp. 876-883, 2001.

[51] J. Argueta-Donohue, N. Carrillo, L. Valdes-Reyes, et al., "Leishmania mexicana: participation of NF- $\kappa \mathrm{B}$ in the differential production of IL-12 in dendritic cells and monocytes induced by lipophosphoglycan (LPG)," Experimental Parasitology, vol. 120, no. 1, pp. 1-9, 2008.

[52] K. Tejle, M. Lindroth, K.-E. Magnusson, and B. Rasmusson, "Wild-type Leishmania donovani promastigotes block maturation, increase integrin expression and inhibit detachment of human monocyte-derived dendritic cells-the influence of phosphoglycans," FEMS Microbiology Letters, vol. 279, no. 1, pp. 92-102, 2008.

[53] M. Ato, S. Stager, C. R. Engwerda, and P. M. Kaye, "Defective CCR7 expression on dendritic cells contributes to the development of visceral leishmaniasis," Nature Immunology, vol. 3, no. 12, pp. 1185-1191, 2002.

[54] H. Jebbari, A. J. Stagg, R. N. Davidson, and S. C. Knight, "Leishmania major promastigotes inhibit dendritic cell motility in vitro," Infection and Immunity, vol. 70, no. 2, pp. 1023-1026, 2002.

[55] A. Ponte-Sucre, D. Heise, and H. Moll, "Leishmania major lipophosphoglycan modulates the phenotype and inhibits migration of murine Langerhans cells," Immunology, vol. 104, no. 4, pp. 462-467, 2001.

[56] D. Liu, C. Kebaier, N. Pakpour, et al., "Leishmania major phosphoglycans influence the host early immune response by modulating dendritic cell functions," Infection and Immunity, vol. 77, no. 8, pp. 3272-3283, 2009.

[57] M. Revest, L. Donaghy, F. Cabillic, C. Guiguen, and J.-P. Gangneux, "Comparison of the immunomodulatory effects of L. donovani and L. major excreted-secreted antigens, particulate and soluble extracts and viable parasites on human dendritic cells," Vaccine, vol. 26, no. 48, pp. 61196123, 2008

[58] C. Wiethe, A. Debus, M. Mohrs, A. Steinkasserer, M. Lutz, and A. Gessner, "Dendritic cell differentiation state and their interaction with NKT cells determine Th1/Th2 differentiation in the murine model of Leishmania major infection," Journal of Immunology, vol. 180, no. 7, pp. 43714381, 2008.

[59] J. Liese, U. Schleicher, and C. Bogdan, "TLR9 signaling is essential for the innate NK cell response in murine cutaneous leishmaniasis," European Journal of Immunology, vol. 37, no. 12, pp. 3424-3434, 2007.

[60] U. Schleicher, J. Liese, I. Knippertz, et al., "NK cell activation in visceral leishmaniasis requires TLR9, myeloid DCs, and IL-12, but is independent of plasmacytoid DCs," Journal of Experimental Medicine, vol. 204, no. 4, pp. 893-906, 2007.

[61] C. De Trez, M. Brait, O. Leo, et al., "Myd88-dependent in vivo maturation of splenic dendritic cells induced by Leishmania donovani and other Leishmania species," Infection and Immunity, vol. 72, no. 2, pp. 824-832, 2004.

[62] I. Becker, N. Salaiza, M. Aguirre, et al., "Leishmania lipophosphoglycan (LPG) activates NK cells through Tolllike receptor-2," Molecular and Biochemical Parasitology, vol. 130, no. 2, pp. 65-74, 2003.

[63] J.-F. Flandin, F. Chano, and A. Descoteaux, "RNA interference reveals a role for TLR2 and TLR3 in the recognition of 
Leishmania donovani promastigotes by interferon- $\boldsymbol{\gamma}$-primed macrophages," European Journal of Immunology, vol. 36, no. 2, pp. 411-420, 2006.

[64] M. J. de Veer, J. M. Curtis, T. M. Baldwin, et al., "MyD88 is essential for clearance of Leishmania major: possible role for lipophosphoglycan and Toll-like receptor 2 signaling," European Journal of Immunology, vol. 33, no. 10, pp. 28222831, 2003.

[65] L. P. Carvalho, E. J. Pearce, and P. Scott, "Functional dichotomy of dendritic cells following interaction with Leishmania braziliensis: infected cells produce high levels of TNF- $\alpha$, whereas bystander dendritic cells are activated to promote T cell responses," Journal of Immunology, vol. 181, no. 9, pp. 6473-6480, 2008.

[66] L. Van Overtvelt, N. Vanderheyde, V. Verhasselt, et al., "Trypanosoma cruzi infects human dendritic cells and prevents their maturation: inhibition of cytokines, HLA-DR, and costimulatory molecules," Infection and Immunity, vol. 67, no. 8, pp. 4033-4040, 1999.

[67] C. Brodskyn, J. Patricio, R. Oliveira, et al., "Glycoinositolphospholipids from Trypanosoma cruzi interfere with macrophages and dendritic cell responses," Infection and Immunity, vol. 70, no. 7, pp. 3736-3743, 2002.

[68] C. V. Poncini, C. D. Alba Soto, E. Batalla, M. E. Solana, and S. M. Gonzalez Cappa, "Trypanosoma cruzi induces regulatory dendritic cells in vitro," Infection and Immunity, vol. 76, no. 6, pp. 2633-2641, 2008.

[69] D. Chaussabel, B. Pajak, V. Vercruysse, et al., "Alteration of migration and maturation of dendritic cells and T-cell depletion in the course of experimental Trypanosoma cruzi infection," Laboratory Investigation, vol. 83, no. 9, pp. 13731382, 2003.

[70] C. D. Alba Soto, G. A. Mirkin, M. E. Solana, and S. M. Gonzalez Cappa, "Trypanosoma cruzi infection modulates in vivo expression of major histocompatibility complex class II molecules on antigen-presenting cells and T-cell stimulatory activity of dendritic cells in a strain-dependent manner," Infection and Immunity, vol. 71, no. 3, pp. 1194-1199, 2003.

[71] L. Planelles, M. C. Thomas, C. Maranon, M. Morell, and M. C. Lopez, "Differential CD86 and CD40 co-stimulatory molecules and cytokine expression pattern induced by Trypanosoma cruzi in APCs from resistant or susceptible mice," Clinical and Experimental Immunology, vol. 131, no. 1, pp. 41-47, 2003.

[72] R. Koga, S. Hamano, H. Kuwata, et al., "TLR-dependent induction of IFN- $\beta$ mediates host defense against Trypanosoma cruzi," Journal of Immunology, vol. 177, no. 10, pp. 7059-7066, 2006.

[73] M. A. S. Campos, I. C. Almeida, O. Takeuchi, et al., "Activation of Toll-like receptor-2 by glycosylphosphatidylinositol anchors from a protozoan parasite," Journal of Immunology, vol. 167, no. 1, pp. 416-423, 2001.

[74] A. Bafica, H. C. Santiago, R. Goldszmid, C. Ropert, R. T. Gazzinelli, and A. Sher, "Cutting edge: TLR9 and TLR2 signaling together account for MyD88-dependent control of parasitemia in Trypanosoma cruzi infection," Journal of Immunology, vol. 177, no. 6, pp. 3515-3519, 2006.

[75] A. Ouaissi, E. Guilvard, Y. Delneste, et al., "The Trypanosoma cruzi Tc52-released protein induces human dendritic cell maturation, signals via Toll-like receptor 2, and confers protection against lethal infection," Journal of Immunology, vol. 168, no. 12, pp. 6366-6374, 2002.

[76] A. C. Monteiro, V. Schmitz, A. Morrot, et al., "Bradykinin B2 Receptors of dendritic cells, acting as sensors of kinins proteolytically released by Trypanosoma cruzi, are critical for the development of protective type-1 responses," PLoS Pathogens, vol. 3, no. 11, article e185, 2007.

[77] C. Reis e Sousa, S. Hieny, T. Scharton-Kersten, et al., "In vivo microbial stimulation induces rapid CD40 ligandindependent production of interleukin 12 by dendritic cells and their redistribution to T cell areas," Journal of Experimental Medicine, vol. 186, no. 11, pp. 1819-1829, 1997.

[78] O. Schulz, A. D. Edwards, M. Schito, et al., "CD40 triggering of heterodimeric IL-12 p70 production by dendritic cells in vivo requires a microbial priming signal," Immunity, vol. 13, no. 4, pp. 453-462, 2000.

[79] J. Aliberti, D. Jankovic, and A. Sher, "Turning it on and off: regulation of dendritic cell function in Toxoplasma gondii infection," Immunological Reviews, vol. 201, pp. 26-34, 2004.

[80] F. Yarovinsky, D. Zhang, J. F. Andersen, et al., "Immunology: TLR11 activation of dendritic cells by a protozoan profilinlike protein," Science, vol. 308, no. 5728, pp. 1626-1629, 2005.

[81] C. M. Miller, N. R. Boulter, R. J. Ikin, and N. C. Smith, "The immunobiology of the innate response to Toxoplasma gondii," International Journal for Parasitology, vol. 39, no. 1, pp. 23-39, 2009.

[82] F. Yarovinsky, "Toll-like receptors and their role in host resistance to Toxoplasma gondii," Immunology Letters, vol. 119, no. 1-2, pp. 17-21, 2008.

[83] J. Aliberti, J. G. Valenzuela, V. B. Carruthers, et al., "Molecular mimicry of a CCR5 binding-domain in the microbial activation of dendritic cells," Nature Immunology, vol. 4, no. 5, pp. 485-490, 2003.

[84] C. Reis e Sousa, G. Yap, O. Schulz, et al., "Paralysis of dendritic cell IL-12 production by microbial products prevents infection-induced immunopathology," Immunity, vol. 11, no. 5, pp. 637-647, 1999.

[85] J. Aliberti and A. Sher, "Role of G-protein-coupled signaling in the induction and regulation of dendritic cell function by Toxoplasma gondii," Microbes and Infection, vol. 4, no. 9, pp. 991-997, 2002

[86] S. Suchitra, K. A. Anbu, D. K. Rathore, M. Mahawar, B. P. Singh, and P. Joshi, "Haemonchus contortus calreticulin binds to C-reactive protein of its host, a novel survival strategy of the parasite," Parasite Immunology, vol. 30, no. 67, pp. 371-374, 2008.

[87] A. S. McKee, F. Dzierszinski, M. Boes, D. S. Roos, and E. J. Pearce, "Functional inactivation of immature dendritic cells by the intracellular parasite Toxoplasma gondii," Journal of Immunology, vol. 173, no. 4, pp. 2632-2640, 2004.

[88] A. L. Bierly, W. J. Shufesky, W. Sukhumavasi, A. E. Morelli, and E. Y. Denkers, "Dendritic cells expressing plasmacytoid marker PDCA-1 are Trojan horses during Toxoplasma gondii infection," Journal of Immunology, vol. 181, no. 12, pp. 84858491, 2008

[89] J. Diana, F. Persat, M.-J. Staquet, et al., "Migration and maturation of human dendritic cells infected with Toxoplasma gondii depend on parasite strain type," FEMS Immunology and Medical Microbiology, vol. 42, no. 3, pp. 321-331, 2004.

[90] N. Courret, S. Darche, P. Sonigo, G. Milon, D. Buzoni-Gatel, and I. Tardieux, "CD11c- and CD11b-expressing mouse leukocytes transport single Toxoplasma gondii tachyzoites to the brain," Blood, vol. 107, no. 1, pp. 309-316, 2006.

[91] C. M. Persson, H. Lambert, P. P. Vutova, et al., "Transmission of Toxoplasma gondii from infected dendritic cells to natural killer cells," Infection and Immunity, vol. 77, no. 3, pp. 970976, 2009. 
[92] H. Lambert, N. Hitziger, I. Dellacasa, M. Svensson, and A. Barragan, "Induction of dendritic cell migration upon Toxoplasma gondii infection potentiates parasite dissemination," Cellular Microbiology, vol. 8, no. 10, pp. 1611-1623, 2006.

[93] J. Diana, C. Vincent, F. Peyron, S. Picot, D. Schmitt, and F. Persat, "Toxoplasma gondii regulates recruitment and migration of human dendritic cells via different soluble secreted factors," Clinical and Experimental Immunology, vol. 141, no. 3, pp. 475-484, 2005.

[94] J. D. Kamda and S. M. Singer, "Phosphoinositide 3-kinasedependent inhibition of dendritic cell interleukin-12 production by Giardia lamblia," Infection and Immunity, vol. 77, no. 2, pp. 685-693, 2009.

[95] C. Maldonado-Bernal, C. J. Kirschning, Y. Rosenstein, et al., "The innate immune response to Entamoeba histolytica lipopeptidophosphoglycan is mediated by Toll-like receptors 2 and 4," Parasite Immunology, vol. 27, no. 4, pp. 127-137, 2005.

[96] C. P. A. Ivory, M. Prystajecky, C. Jobin, and K. Chadee, "Toll-like receptor 9-dependent macrophage activation by Entamoeba histolytica DNA," Infection and Immunity, vol. 76, no. 1, pp. 289-297, 2008.

[97] H. Vivanco-Cid, C. Alpuche-Aranda, I. Wong-Baeza, et al., "Lipopopeptidephosphoglycan from Entamoeba histolytica activates human macrophages and dendritic cells and reaches their late endosomes," Parasite Immunology, vol. 29, no. 9, pp. 467-474, 2007.

[98] C. P. A. Ivory and K. Chadee, "Activation of dendritic cells by the Gal-lectin of Entamoeba histolytica drives Th1 responses in vitro and in vivo," European Journal of Immunology, vol. 37, no. 2, pp. 385-394, 2007.

[99] K. A. Rogers, A. B. Rogers, B. A. Leav, et al., "MyD88dependent pathways mediate resistance to Cryptosporidium parvum infection in mice," Infection and Immunity, vol. 74, no. 1, pp. 549-556, 2006.

[100] X.-M. Chen, S. P. O’Hara, J. B. Nelson, et al., "Multiple TLRs are expressed in human cholangiocytes and mediate host epithelial defense responses to Cryptosporidium parvum via activation of NF- $\kappa \mathrm{B}$," Journal of Immunology, vol. 175, no. 11, pp. 7447-7456, 2005.

[101] J.-H. Chang, J.-Y. Park, and S.-K. Kim, "Dependence on p38 MAPK signalling in the up-regulation of TLR2, TLR4 and TLR9 gene expression in Trichomonas vaginalis-treated HeLa cells," Immunology, vol. 118, no. 2, pp. 164-170, 2006.

[102] M. R. Zariffard, S. Harwani, R. M. Novak, P. J. Graham, X. Ji, and G. T. Spear, "Trichomonas vaginalis infection activates cells through Toll-like receptor 4," Clinical Immunology, vol. 111, no. 1, pp. 103-107, 2004.

[103] R. T. Semnani, P. G. Venugopal, C. A. Leifer, S. Mostbock, H. Sabzevari, and T. B. Nutman, "Inhibition of TLR3 and TLR4 function and expression in human dendritic cells by helminth parasites," Blood, vol. 112, no. 4, pp. 1290-1298, 2008.

[104] A. Yoshimura, T. Naka, and M. Kubo, "SOCS proteins, cytokine signalling and immune regulation," Nature Reviews Immunology, vol. 7, no. 6, pp. 454-465, 2007.

[105] A. Balic, Y. Harcus, M. J. Holland, and R. M. Maizels, "Selective maturation of dendritic cells by Nippostrongylus brasiliensis-secreted proteins drives Th2 immune responses," European Journal of Immunology, vol. 34, no. 11, pp. 30473059, 2004.

[106] B. W. McConchie, H. H. Norris, V. G. Bundoc, et al., "Ascaris suum-derived products suppress mucosal allergic inflammation in an interleukin-10-independent manner via interference with dendritic cell function," Infection and Immunity, vol. 74, no. 12, pp. 6632-6641, 2006.

[107] D. E. Kean, I. Ohtsuka, K. Sato, et al., "Dissecting Ascaris glycosphingolipids for immunomodulatory moieties- the use of synthetic structural glycosphingolipid analogues," Parasite Immunology, vol. 28, no. 3, pp. 69-76, 2006.

[108] H. S. Goodridge, F. A. Marshall, K. J. Else, et al., "Immunomodulation via novel use of TLR4 by the filarial nematode phosphorylcholine-containing secreted product, ES-62," Journal of Immunology, vol. 174, no. 1, pp. 284-293, 2005.

[109] W. Harnett, M. R. Deehan, K. M. Houston, and M. M. Harnett, "Immunomodulatory properties of a phosphorylcholine-containing secreted filarial glycoprotein," Parasite Immunology, vol. 21, no. 12, pp. 601-608, 1999.

[110] M. Whelan, M. M. Harnett, K. M. Houston, V. Patel, W. Harnett, and K. P. Rigley, "A filarial nematode-secreted product signals dendritic cells to acquire a phenotype that drives development of Th2 cells," Journal of Immunology, vol. 164, no. 12, pp. 6453-6460, 2000.

[111] K. N. Couper, W. Chen, K. M. Houston, W. Harnett, and L. L. Johnson, "ES-62 is unable to modulate Toxoplasma gondiidriven Th1 responses and pathology," Parasite Immunology, vol. 27, no. 4, pp. 147-150, 2005.

[112] L. Al-Riyami, C. A. Egan, J. E. Bradley, S. Lustigman, and W. Harnett, "Failure of ES-62 to inhibit T-helper type 1 responses to other filarial nematode antigens," Parasite Immunology, vol. 30, no. 5, pp. 304-308, 2008.

[113] M. Segura, Z. Su, C. Piccirillo, and M. M. Stevenson, "Impairment of dendritic cell function by excretorysecretory products: a potential mechanism for nematodeinduced immunosuppression," European Journal of Immunology, vol. 37, no. 7, pp. 1887-1904, 2007.

[114] C.-C. Chen, S. Louie, B. A. McCormick, W. A. Walker, and H. N. Shi, "Helminth-primed dendritic cells alter the host response to enteric bacterial infection," Journal of Immunology, vol. 176, no. 1, pp. 472-483, 2006.

[115] E. van Riet, B. Everts, K. Retra, et al., "Combined TLR2 and TLR4 ligation in the context of bacterial or helminth extracts in human monocyte derived dendritic cells: molecular correlates for Th1/Th2 polarization," BMC Immunology, vol. 10, article 9, 2009.

[116] J. Rzepecka, S. Rausch, C. Klotz, et al., "Calreticulin from the intestinal nematode Heligmosomoides polygyrus is a Th2-skewing protein and interacts with murine scavenger receptor-A," Molecular Immunology, vol. 46, no. 6, pp. 1109 $1119,2009$.

[117] C. Cabezon, G. Cabrera, R. Paredes, A. Ferreira, and N. Galanti, "Echinococcus granulosus calreticulin: molecular characterization and hydatid cyst localization," Molecular Immunology, vol. 45, no. 5, pp. 1431-1438, 2008.

[118] F. Guillou, E. Roger, Y. Mone, et al., "Excretory-secretory proteome of larval Schistosoma mansoni and Echinostoma caproni, two parasites of Biomphalaria glabrata," Molecular and Biochemical Parasitology, vol. 155, no. 1, pp. 45-56, 2007.

[119] F. Mendlovic, J. Carrillo-Farga, J. Torres, J. P. Laclette, and A. Flisser, "Differential expression of calreticulin in developmental stages of Taenia solium," Journal of Parasitology, vol. 92, no. 4, pp. 789-795, 2006.

[120] J. A. Winter, O. R. Davies, A. P. Brown, M. C. Garnett, S. Stolnik, and D. Pritchard, "The assessment of hookworm calreticulin as a potential vaccine for necatoriasis," Parasite Immunology, vol. 27, no. 4, pp. 139-146, 2005. 
[121] D. I. Pritchard, A. Brown, G. Kasper, et al., "A hookworm allergen which strongly resembles calreticulin," Parasite Immunology, vol. 21, no. 9, pp. 439-450, 1999.

[122] A. T. Vella, M. D. Hulsebosch, and E. J. Pearce, "Schistosoma mansoni eggs induce antigen-responsive CD44-hi T helper 2 cells and IL-4-secreting CD44-lo cells: potential for T helper 2 subset differentiation is evident at the precursor level," Journal of Immunology, vol. 149, no. 5, pp. 1714-1722, 1992.

[123] G. A. Cook, A. Metwali, A. Blum, R. Mathew, and J. V. Weinstock, "Lymphokine expression in granulomas of Schistosoma mansoni-infected mice," Cellular Immunology, vol. 152, no. 1, pp. 49-58, 1993.

[124] C. Faveeuw, T. Mallevaey, K. Paschinger, et al., "Schistosome $\mathrm{N}$-glycans containing core $\alpha 3$-fucose and core $\beta 2$-xylose epitopes are strong inducers of Th2 responses in mice," European Journal of Immunology, vol. 33, no. 5, pp. 12711281, 2003.

[125] C. M. Kane, L. Cervi, J. Sun, et al., "Helminth antigens modulate TLR-initiated dendritic cell activation," Journal of Immunology, vol. 173, no. 12, pp. 7454-7461, 2004.

[126] C. M. Kane, E. Jung, and E. J. Pearce, "Schistosoma mansoni egg antigen-mediated modulation of Toll-like receptor (TLR)-induced activation occurs independently of TLR2, TLR4, and MyD88," Infection and Immunity, vol. 76, no. 12, pp. 5754-5759, 2008.

[127] J. P. Hewitson, J. R. Grainger, and R. M. Maizels, "Helminth immunoregulation: the role of parasite secreted proteins in modulating host immunity," Molecular and Biochemical Parasitology, vol. 167, no. 1, pp. 1-11, 2009.

[128] P. G. Thomas, M. R. Carter, A. A. Da’Dara, T. M. DeSimone, and D. A. Harn, "A helminth glycan induces APC maturation via alternative NF- $\kappa \mathrm{B}$ activation independent of $\mathrm{I} \kappa \mathrm{B} \alpha$ degradation," Journal of Immunology, vol. 175, no. 4, pp. 2082 2090, 2005.

[129] S. P. Saunders, C. M. Walsh, J. L. Barlow, et al., "The C-type lectin SIGNR1 binds Schistosoma mansoni antigens in vitro, but SIGNR1-deficient mice have normal responses during schistosome infection," Infection and Immunity, vol. 77, no. 1, pp. 399-404, 2009.

[130] C. M. Krawczyk, J. Sun, and E. J. Pearce, "Th2 differentiation is unaffected by jagged 2 expression on dendritic cells," Journal of Immunology, vol. 180, no. 12, pp. 7931-7937, 2008.

[131] T. B. H. Geijtenbeek and S. I. Gringhuis, "Signalling through C-type lectin receptors: shaping immune responses," Nature Reviews Immunology, vol. 9, no. 7, pp. 465-479, 2009.

[132] L. Gomez-Garcia, I. Rivera-Montoya, M. Rodriguez-Sosa, and L. I. Terrazas, "Carbohydrate components of Taenia crassiceps metacestodes display Th2-adjuvant and antiinflammatory properties when co-injected with bystander antigen," Parasitology Research, vol. 99, no. 4, pp. 440-448, 2006.

[133] L. Gomez-Garcia, L. M. Lopez-Marin, R. Saavedra, J. L. Reyes, M. Rodriguez-Sosa, and L. I. Terrazas, "Intact glycans from cestode antigens are involved in innate activation of myeloid suppressor cells," Parasite Immunology, vol. 27, no. 10-11, pp. 395-405, 2005.

[134] J. L. Reyes, C. A. Terrazas, L. Vera-Arias, and L. I. Terrazas, "Differential response of antigen presenting cells from susceptible and resistant strains of mice to Taenia crassiceps infection," Infection, Genetics and Evolution, vol. 9, no. 6, pp. 1115-1127, 2009.

[135] E. Muraille, C. De Trez, M. Brait, P. De Baetselier, O. Leo, and Y. Carlier, "Genetically resistant mice lacking MyD88adapter protein display a high susceptibility to Leishmania major infection associated with a polarized Th2 response," Journal of Immunology, vol. 170, no. 8, pp. 4237-4241, 2003.

[136] J. Aliberti, "Host persistence: exploitation of antiinflammatory pathways by Toxoplasma gondii," Nature Reviews Immunology, vol. 5, no. 2, pp. 162-170, 2005.

[137] F. S. Machado, L. Esper, A. Dias, et al., "Native and aspirintriggered lipoxins control innate immunity by inducing proteasomal degradation of TRAF6," Journal of Experimental Medicine, vol. 205, no. 5, pp. 1077-1086, 2008.

[138] A. Langenkamp, M. Messi, A. Lanzavecchia, and F. Sallusto, "Kinetics of dendritic cell activation: impact on priming of TH1,TH2 and nonpolarized T cells," Nature Immunology, vol. 1, no. 4, pp. 311-316, 2000.

[139] P. Kalinski, J. H. N. Schuitemaker, C. M. U. Hilkens, E. A. Wierenga, and M. L. Kapsenberg, "Final maturation of dendritic cells is associated with impaired responsiveness to IFN- $\gamma$ and to bacterial IL-12 inducers: decreased ability of mature dendritic cells to produce IL-12 during the interaction with Th cells," Journal of Immunology, vol. 162, no. 6, pp. 3231-3236, 1999.

[140] A. S. MacDonald and R. M. Maizels, "Alarming dendritic cells for Th2 induction," Journal of Experimental Medicine, vol. 205, no. 1, pp. 13-17, 2008.

[141] L. Carvalho, J. Sun, C. Kane, F. Marshall, C. Krawczyk, and E. J. Pearce, "Review series on helminths, immune modulation and the hygiene hypothesis: mechanisms underlying helminth modulation of dendritic cell function," Immunology, vol. 126, no. 1, pp. 28-34, 2009.

[142] S. J. Jenkins, G. Perona-Wright, A. G. F. Worsley, N. Ishii, and A. S. MacDonald, "Dendritic cell expression of OX40 ligand acts as a costimulatory, not polarizing, signal for optimal Th2 priming and memory induction in vivo," Journal of Immunology, vol. 179, no. 6, pp. 3515-3523, 2007.

[143] F. A. Marshall and E. J. Pearce, "Uncoupling of induced protein processing from maturation in dendritic cells exposed to a highly antigenic preparation from a helminth parasite," Journal of Immunology, vol. 181, no. 11, pp. 7562-7570, 2008.

[144] E. Caparros, P. Munoz, E. Sierra-Filardi, et al., "DC-SIGN ligation on dendritic cells results in ERK and PI3K activation and modulates cytokine production," Blood, vol. 107, no. 10, pp. 3950-3958, 2006.

[145] S. I. Gringhuis, J. den Dunnen, M. Litjens, B. van het Hof, Y. van Kooyk, and T. H. Geijtenbeek, "C-type lectin DC-SIGN modulates Toll-like receptor signaling via Raf-1 kinase-dependent acetylation of transcription factor NF- $\kappa \mathrm{B}$," Immunity, vol. 26, no. 5, pp. 605-616, 2007.

[146] T. B. H. Geijtenbeek, S. J. Van Vliet, E. A. Koppel, et al., "Mycobacteria target DC-SIGN to suppress dendritic cell function," Journal of Experimental Medicine, vol. 197, no. 1, pp. 7-17, 2003.

[147] M. Ando, W. Tu, K.-I. Nishijima, and S. Iijima, "Siglec9 enhances IL-10 production in macrophages via tyrosinebased motifs," Biochemical and Biophysical Research Communications, vol. 369, no. 3, pp. 878-883, 2008.

[148] A. F. Carlin, S. Uchiyama, Y.-C. Chang, A. L. Lewis, V. Nizet, and A. Varki, "Molecular mimicry of host sialylated glycans allows a bacterial pathogen to engage neutrophil Siglec-9 and dampen the innate immune response," Blood, vol. 113, no. 14, pp. 3333-3336, 2009.

[149] K. M. Ardeshna, A. R. Pizzey, S. Devereux, and A. Khwaja, "The PI3 kinase, p38 SAP kinase, and NF- $\kappa$ B signal transduction pathways are involved in the survival and maturation of lipopolysaccharide-stimulated human monocyte-derived dendritic cells," Blood, vol. 96, no. 3, pp. 1039-1046, 2000. 
[150] A. Puig-Kroger, M. Relloso, O. Fernandez-Capetillo, et al., "Extracellular signal-regulated protein kinase signaling pathway negatively regulates the phenotypic and functional maturation of monocyte-derived human dendritic cells," Blood, vol. 98, no. 7, pp. 2175-2182, 2001.

[151] T. Fukao, M. Tanabe, Y. Terauchi, et al., "P13K-mediated negative feedback regulation of IL-12 production in DCs," Nature Immunology, vol. 3, no. 9, pp. 875-881, 2002.

[152] C.-H. Chen, H. Floyd, N. E. Olson, et al., "Dendritic-cellassociated C-type lectin 2 (DCAL-2) alters dendritic-cell maturation and cytokine production," Blood, vol. 107, no. 4, pp. 1459-1467, 2006.

[153] S. Suchitra, K. A. Anbu, D. K. Rathore, M. Mahawar, B. P. Singh, and P. Joshi, "Haemonchus contortus calreticulin binds to C-reactive protein of its host, a novel survival strategy of the parasite," Parasite Immunology, vol. 30, no. 67, pp. 371-374, 2008.

[154] T. B. H. Geijtenbeek and S. I. Gringhuis, "Signalling through C-type lectin receptors: shaping immune responses," Nature Reviews Immunology, vol. 9, no. 7, pp. 465-479, 2009. 

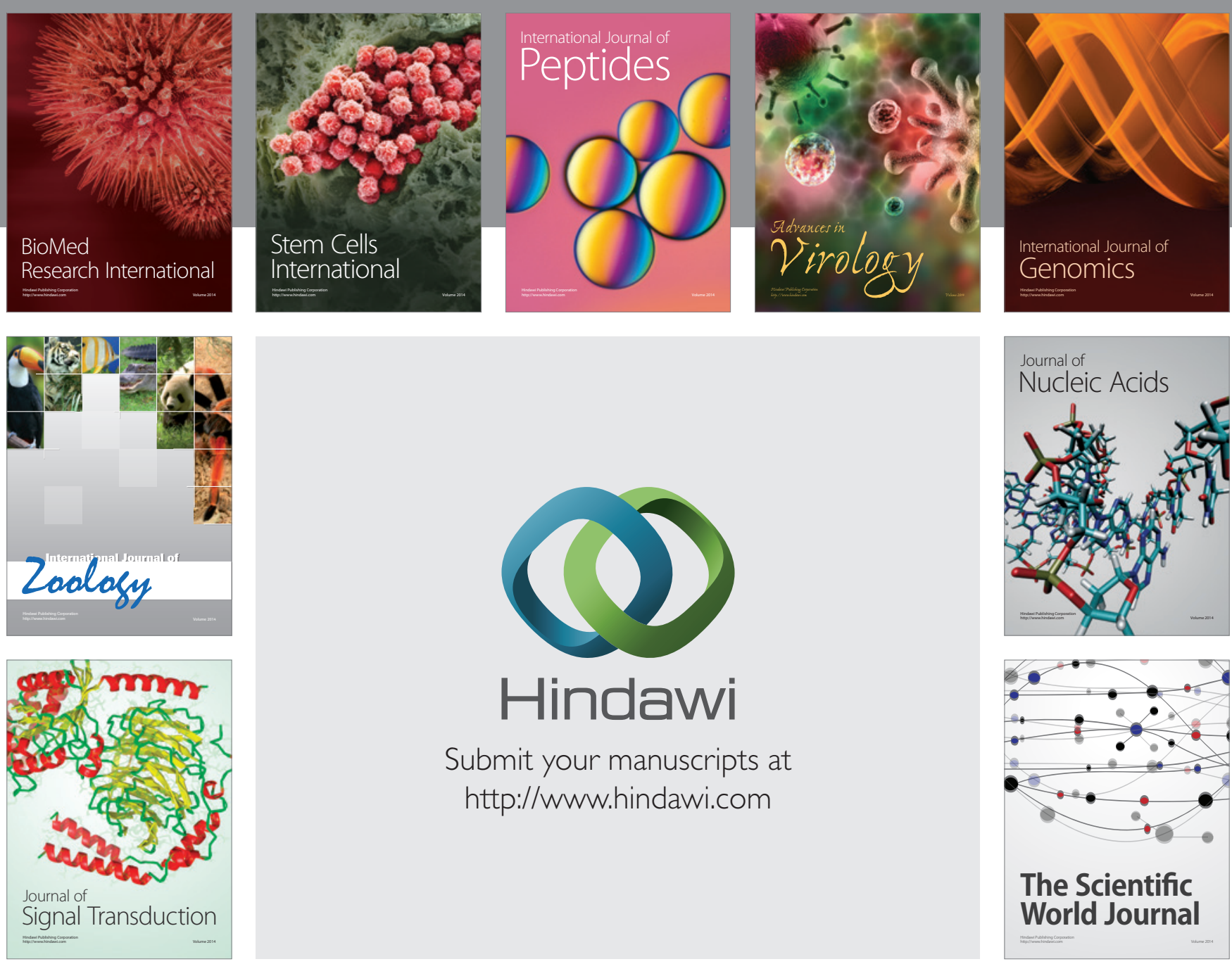

Submit your manuscripts at

http://www.hindawi.com
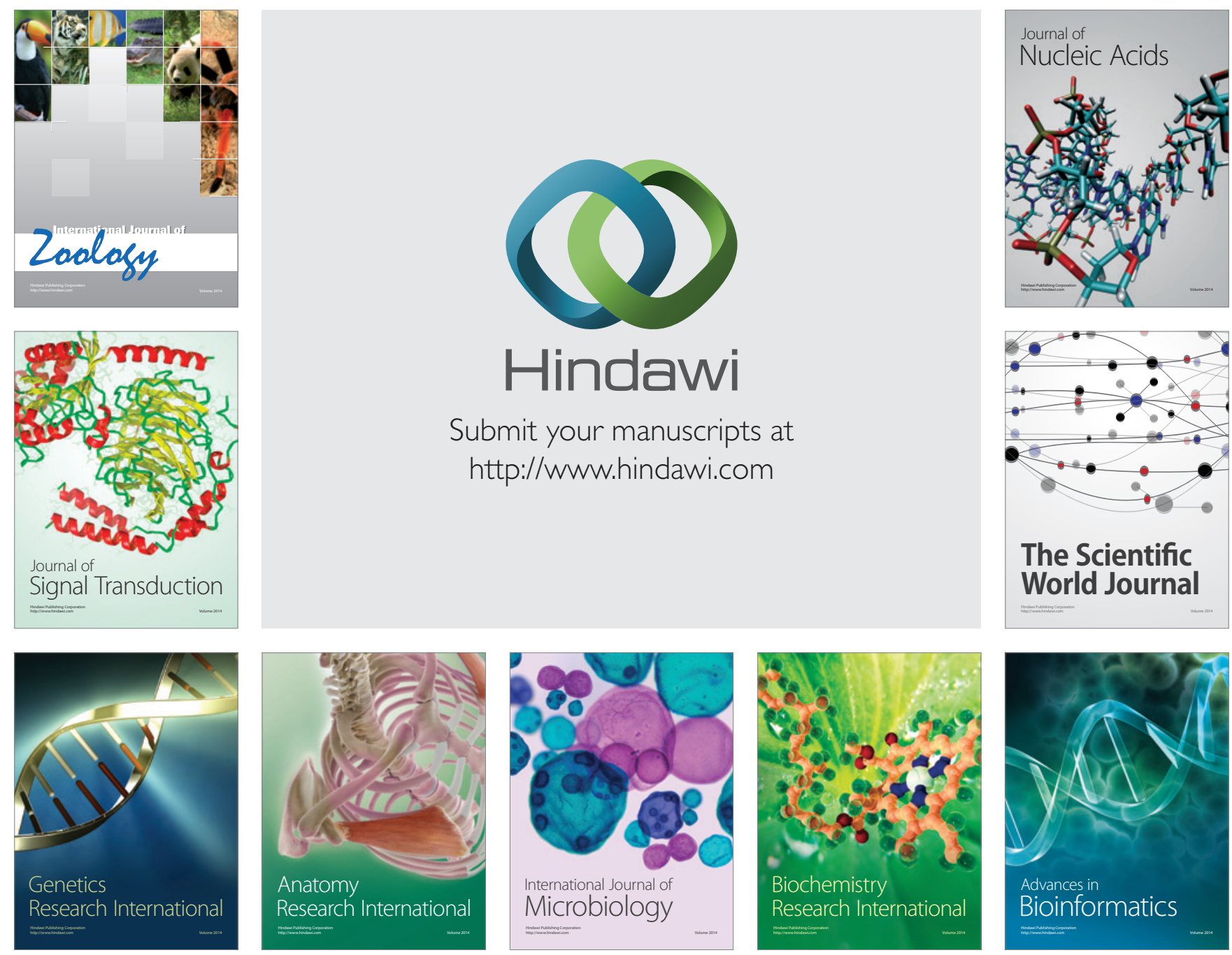

The Scientific World Journal
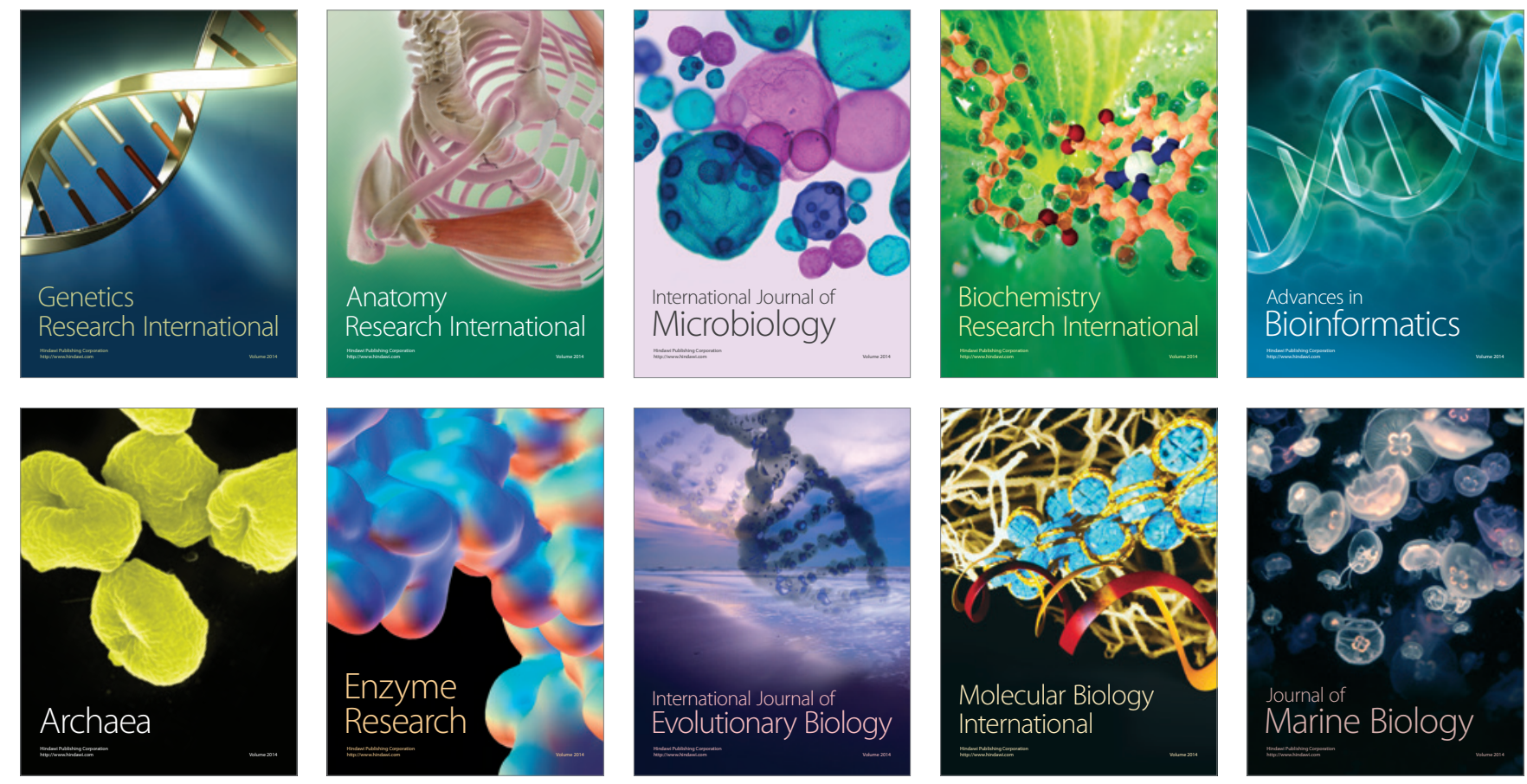